\title{
The US oil supply revolution and the global economy
}

\author{
Kamiar Mohaddes $^{1} \cdot$ Mehdi Raissi $^{2}$ \\ Received: 28 January 2016 / Accepted: 25 May 2018 / Published online: 3 July 2018 \\ (c) The Author(s) 2018
}

\begin{abstract}
This paper investigates the global macroeconomic consequences of falling oil prices due to the oil revolution in the USA, using a global VAR model estimated for 38 countries/regions over the period 1979Q2-2011Q2. Set identification of the US oil supply shock is achieved through imposing dynamic sign restrictions on the impulse responses of the model. The results show that there are considerable heterogeneities in the responses of different countries to a US supply-driven oil price shock, with real GDP increasing in both advanced and emerging market oil-importing economies, output declining in commodity exporters, inflation falling in most countries, and equity prices rising worldwide. Overall, our results suggest that a US supply-driven oil price shock (equivalent to a 10-12\% fall per quarter in the price of oil) results in an increase in global growth by $0.16-0.37$ percentage points in the medium term. This is mainly due to an increase in spending by oil-importing countries, which exceeds the decline in expenditure by oil exporters.
\end{abstract}

Keywords Tight oil · Shale oil · Fracking revolution · Oil price decline · Oil supply · Global macroeconometric modeling · International business cycle

JEL Classification C32 $\cdot$ E17 $\cdot$ F44 $\cdot$ F47 $\cdot$ O13 $\cdot$ Q43

\begin{abstract}
We are grateful to Paul Cashin, Ibrahim A. Elbadawi, Akito Matsumoto, Sergio L. Rodriguez, Hoda Selim, SeokHyun Yoon and seminar participants at the IMF and the Energy Policy Research Group Conference Call (University of Cambridge) as well as conference participants at the Oil, Middle East, and the Global Economy Conference (USC Dornsife INET) for helpful comments and suggestions. We would also like to thank the editor in charge of our paper and two anonymous referees for helpful suggestions. Kamiar Mohaddes gratefully acknowledges financial support from the Economic Research Forum (ERF). The views expressed in this paper are those of the authors and do not necessarily represent those of the International Monetary Fund, IMF policy, or the ERF..
\end{abstract}

Kamiar Mohaddes km418@cam.ac.uk

1 Faculty of Economics and Girton College, University of Cambridge, Cambridge, UK

2 International Monetary Fund, Washington, DC, USA 


\section{Introduction}

The technological advancements over the last decade have not only reduced the costs associated with the production of unconventional oil, but also made extraction of tight oil resemble a manufacturing process in which one can adjust production in response to price changes with relative ease. This is in stark contrast to other extraction methods (e.g., offshore extraction), which require large upfront spending and involve relatively long lead times, and more importantly, once the process is operational, changing the quantity produced can be difficult. Therefore, one of the implications of the recent oil revolution ${ }^{1}$ is that US production can play a significant role in balancing global demand and supply, and this in turn implies that the current low oil price environment could be persistent.

This paper investigates the macroeconomic consequences of the US oil revolution for the global economy in general and the Middle East and North Africa (MENA) region in particular in terms of its effects on real output, oil prices, and financial markets. We integrate an oil price equation, which takes account of developments in the world economy as well as the prevailing oil supply conditions, within a compact quarterly model of the global economy using a dynamic multi-country framework first advanced by Pesaran et al. (2004), known as the global VAR (or GVAR for short). This approach enables one to analyze the international macroeconomic transmission of shocks, taking into account not only the direct exposure of countries to the shocks but also the indirect effects through secondary or tertiary channels. To distinguish the US oil revolution from other supply shocks, such as disruptions caused by geopolitical tensions in the Middle East, and oil demand shocks in general, we employ a set of dynamic sign restrictions on the impulse responses of our GVAR-Oil model. In addition to restricting oil prices and production levels, the global dimension of the GVAR-Oil model offers an intuitive way of imposing a large number of additional cross-country sign restrictions that greatly reduces the number of admissible structural models. ${ }^{2}$

Our dynamic multi-country framework consists of 38 country-/region-specific models, among which is a single Euro Area region (including 8 of the 11 countries that joined Euro in 1999) as well as the countries of the Gulf Cooperation Council (GCC). These individual models are solved in a global setting where core macroeconomic variables of each economy are related to corresponding foreign variables-which have been constructed to match the international trade pattern of the country under consideration and serve as a proxy for common unobserved factors. The model has both real and financial variables: real GDP, inflation, real equity prices, real exchange rate, short- and long-term interest rates, OPEC and non-OPEC oil production, and the price of oil. Our framework is able to account for various transmission channels, including not only trade relationships but also financial linkages through interest rates, equity prices, and exchange rates; see Dees et al. (2007) and Pesaran et al. (2007). We estimate the oil price equation and the 38 individual vector autoregressive models

1 Oil production in the USA increased by about 4.3 million barrels per day over the last seven years.

2 Note that the collapse in the price of oil after June 2014 is only partly driven by the fracking boom in the USA. The slowdown in global demand has also played an important role. Investigating the role of demand factors (either speculative or physical) in driving crude oil prices, while possible within a sign-restricted GVAR context (see Cashin et al. 2014), is beyond the scope of this paper. 


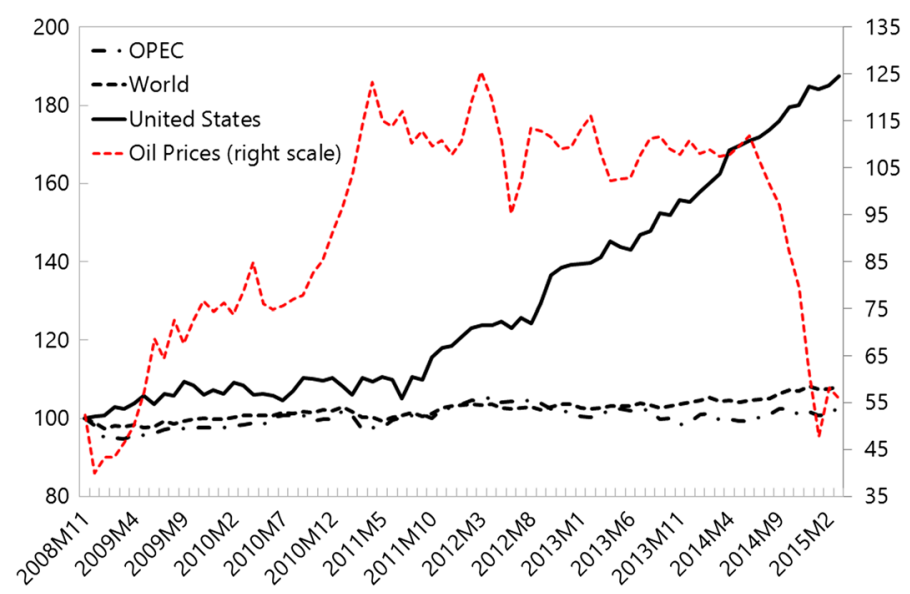

Fig. 1 Oil production and brent oil prices, 2008M11-2015M3. Notes: Oil production is indexed to 100 in November 2008. Brent oil prices are in US dollars per barrel. Source: Authors' calculations based on data from the U.S. Energy Information Administration Monthly Energy Review and Federal Reserve Economic Data (FRED)

with foreign variables (VARX* models) over the period 1979Q2-2011Q2. ${ }^{3}$ Having combined the estimates from the oil price equation with those of the country-specific VARX* models, we solve the GVAR-Oil model and examine the effects of a US oil supply shock (while keeping the level of oil supply in Saudi Arabia constant, and abstracting from the effects of global demand slowdown on oil prices) on the macroeconomic variables of different countries (both commodity importers and exporters), including the MENA region. Figure 1 shows that while OPEC oil production remained relatively stable over 2008M1-2015M3, that of the USA increased by around $87 \%$ over this period, increasing world oil production by about $8 \%$. As can be seen, the US oil revolution coincided with a drop in oil prices of over $50 \%$ recently.

The results indicate that while oil importers typically face a long-lived rise in economic activity (ranging between $0.04 \%$ and $0.95 \%$ ) in response to a US supplydriven fall in oil prices, the impact is negative for energy exporters (being on average $-2.14 \%$ for the GCC, $-1.32 \%$ for other MENA oil exporters, and $-0.41 \%$ for Latin America), mainly because lower oil prices weaken domestic demand as well as external and fiscal balances in these countries. To investigate the channels through which the fall in oil revenues affects oil exporters (as well as select oil importers), especially in the long run, and quantify its growth impact, we embed the long-run output relation of Esfahani et al. (2014) in individual VARX* models. Our results indicate that oil revenue shocks (such as those from the low oil price environment we are currently

\footnotetext{
3 Extending the sample beyond 2011Q2 is not feasible due to the Arab Spring which affected several of the countries in our sample (e.g., Syria, Libya). Nonetheless, since 1980, there have been seven episodes of oil price collapse (i.e., Brent crude oil prices falling by at least 25 percent) — six of them are already captured by our time series (from 1979Q2 to 2011Q2). Moreover, the secular decline in US oil production that began in the early 1970s reversed in November 2008 largely due to the US fracking boom. We follow Kilian (2017) in treating November 2008 as the beginning of the fracking boom, and therefore, argue that our time series already capture an important part of the US oil production increase.
} 
experiencing) have a large, long-lasting, and significant impact on these economies' growth paths operating through the capital accumulation channel.

Negative growth effects (albeit smaller) are also observed for energy importers which have strong economic ties with oil exporters, through spillover effects. In particular, for most oil importers in the MENA region, gains from lower oil prices are offset by a decline in external demand/financing by MENA oil exporters given strong linkages between the two groups through trade, remittances, tourism, foreign direct investment, and grants. ${ }^{4}$ These economies on average experience a fall in real output of about $0.28 \%$. For several countries in this group, low pass-through from lower global oil prices to domestic fuel prices limits the impact on disposable incomes of consumers and profit margins of firms and therefore contains the positive effect on economic growth of lower oil prices in these countries.

Finally, in response to a positive US oil supply disturbance, almost all countries in our sample experience long-run disinflation pressures and an increase in equity prices (apart from commodity exporters). Overall, our findings suggest that as a result of the US oil revolution, with oil prices falling by about 10-12\% below their pre-shock levels per quarter, and a larger fall at peak (i.e., after one year), global growth increases by about $0.16-0.37$ percentage points over the medium term. This is mainly due to an increase in spending by oil importers which exceeds the decline in expenditure by oil exporters.

The collapse of oil prices from around $\$ 114$ in June 2014 to $\$ 31$ in January 2016 has led to a large body of literature analyzing the causes of this steep oil price drop and its macroeconomic implications. However, most of this literature is based on descriptive analyses, mainly written by international organizations (see, for instance, the IMF blog by Arezki and Blanchard 2014), investment banks (such as Goldman Sachs Global Investment Research division's report on “The New Oil Order"), various (energy) economists, and of course mostly internal reports by oil and gas companies (which are used to inform exploration, development, and hiring decisions). Notable exceptions are Baumeister and Kilian (2015) who emphasize the role of demand factors in explaining the behavior of oil prices; Baffes et al. (2015), Husain et al. (2015), and Mânescu and Nuño (2015) who argue that supply (rather than demand) factors played the largest role; and Mohaddes and Pesaran (2017) who illustrate that the effects of oil prices on the global economy is not different this time around, with the recent plunge in oil prices contributing positively to the US economy.

More broadly, most papers in the literature that investigate the effects of oil shocks on macroeconomic variables have focused on a handful of industrialized/OECD countries, and in most cases, they have looked at the impact of oil shocks exclusively on the USA and in isolation from the rest of the world. Moreover, the focus of those analyses has predominantly been on net oil importers - see, for example, Hamilton (2009), Kilian (2009), and Peersman and Van Robays (2012). An exception is the work of Cashin et al. (2014), who look at the differential effects of oil demand and supply shocks on the global economy, Esfahani et al. (2014), who conduct a country-by-country VARX* analysis looking at the direct effects of oil revenue shocks on domestic output for nine major oil exporters (six of which are OPEC members); Kilian et al. (2009),

4 An exception is Egypt for which the impact is positive due to other idiosyncratic factors. 
who examine the effects of different types of oil price shocks on the external balances of net oil exporters/importers; and Mohaddes and Pesaran (2016), who examine the effects of country-specific shocks (to Iranian and Saudi Arabian oil output) on the world economy.

In this paper, we extend the literature in a number of respects. Firstly, our paper is complementary to the analysis of the effects of oil price shocks on advanced economies, given its wide country coverage, including both major oil exporters (located in the Middle East, Africa, and Latin America) and many developing countries. We are therefore able to analyze the macroeconomic consequences of US supply-driven oil price shocks across a wide range of developed and developing countries (including oil exporters) that are structurally very diverse with respect to the role of oil and other forms of energy in their economies. We do not attempt to conduct a historical decomposition of oil price fluctuations and/or to exactly identify all causes of the recent oil price collapse, but to only focus on the international macroeconomic implications of the tight oil revolution in the USA. We achieve this objective with our set of identifying sign restrictions without the need to pin down all other determinants of oil price fluctuations (including demand factors and/or the reaction of Saudi Arabia to the tight oil revolution). Secondly, we provide a compact model of the world economy that takes into account the economic interlinkages and spillovers (direct exposure of countries to the shocks but also the indirect effects through secondary or tertiary channels) that exist between different regions (which may also shape the responses of different macroeconomic variables to oil price shocks), rather than undertaking a descriptive analysis or a country-by-country structural VAR study of the oil market. Thirdly, we include oil production endogenously in the US and the GCC models, while modeling oil prices as determined in the global oil market. This is required to answer counterfactual questions regarding the possible macroeconomic effects of the US oil revolution. Finally, we demonstrate how our GVAR-Oil model, covering over $90 \%$ of world GDP, $85 \%$ of world oil consumption, and $80 \%$ of world's proven oil reserves, can be used for "set-identified" impulse response analysis and to obtain a better understanding of structural shocks. In particular, we set-identify the US oil supply shock ${ }^{5}$ by imposing dynamic sign restrictions on the impulse responses of oil production in the USA, GCC oil supply, and GDP of major oil importers in our sample. ${ }^{6}$

The rest of the paper is organized as follows. Section 2 describes the GVAR methodology, outlines our model specifications, and illustrates how we integrate the oil market within our framework. Section 3 provides the estimates for the country-specific models, presents our identification strategy, and examines the direct and indirect effects of shocks to US oil output on the world economy, on a country-by-country basis, and provide the time profile of the effects of country-specific oil shocks on real output inflation, and real equity prices across countries. Section 4 investigates in greater detail the macroeconomic implications of the US oil supply revolution, in terms of its

\footnotetext{
5 A positive US oil supply shock is an exogenous shift of the oil supply curve along the oil demand schedule to the right, increasing oil production, and lowering oil prices.

6 Cashin et al. (2014) show that the cross-sectional dimension of the GVAR provides a large number of additional cross-country identifying restrictions and reduces the set of admissible structural impulse responses.
} 
real GDP effects, on individual countries in the MENA region over the short and long term. Finally, Sect. 5 concludes.

\section{Modeling the oil-macroeconomy relationship in a global context}

To analyze the international macroeconomic transmission of the US oil revolution shock, we need to model the oil-macroeconomy relationship in a global context. To this end, we integrate an oil price equation within a compact quarterly model of the global economy using the GVAR framework. The resulting GVAR-Oil model takes into account both the temporal and cross-sectional dimensions of the data; real and financial drivers of economic activity; interlinkages and spillovers that exist between different regions; and the effects of unobserved or observed common factors. This is crucial as the impact of the recent oil revolution cannot be reduced to just the USA (where the shock originates) but rather involves multiple regions, and may be amplified or dampened (through a number of channels) depending on the degree of openness of the countries, their trade structure, as well as the strength of global demand. Before describing our approach in modeling individual countries and the global oil market, we provide a short exposition of the GVAR methodology below.

\subsection{The global VAR (GVAR) methodology}

We consider $N$ countries in the global economy, indexed by $i=1, \ldots, N$. With the exception of the USA, all other $N-1$ countries are modeled as small open economies. This set of individual country-specific vector autoregressive models with foreign variables (VARX* models) is used to build the GVAR framework. Following Pesaran (2004) and Dees et al. (2007), a VARX* $\left(p_{i}, q_{i}\right)$ model for the $i$ th country relates a $k_{i} \times 1$ vector of domestic macroeconomic variables (treated as endogenous), $\mathbf{x}_{i t}$, to a $k_{i}^{*} \times 1$ vector of country-specific foreign variables (taken to be weakly exogenous), $\mathbf{x}_{i t}^{*}$,

$$
\boldsymbol{\Phi}_{i}\left(L, p_{i}\right) \mathbf{x}_{i t}=\mathbf{a}_{i 0}+\mathbf{a}_{i 1} t+\boldsymbol{\Lambda}_{i}\left(L, q_{i}\right) \mathbf{x}_{i t}^{*}+\mathbf{u}_{i t},
$$

for $t=1,2, \ldots, T$, where $\mathbf{a}_{i 0}$ and $\mathbf{a}_{i 1}$ are $k_{i} \times 1$ vectors of fixed intercepts and coefficients on the deterministic time trends, respectively, and $\mathbf{u}_{i t}$ is a $k_{i} \times 1$ vector of country-specific shocks, which we assume are serially uncorrelated with zero mean and a non-singular covariance matrix, $\boldsymbol{\Sigma}_{i i}$, namely $\mathbf{u}_{i t} \sim i . i . d .\left(0, \boldsymbol{\Sigma}_{i i}\right)$. For algebraic simplicity, we abstract from observed global factors in the country-specific VARX* models. Furthermore, $\boldsymbol{\Phi}_{i}\left(L, p_{i}\right)=I-\sum_{i=1}^{p_{i}} \boldsymbol{\Phi}_{i} L^{i}$ and $\boldsymbol{\Lambda}_{i}\left(L, q_{i}\right)=\sum_{i=0}^{q_{i}} \boldsymbol{\Lambda}_{i} L^{i}$ are the matrix lag polynomial of the coefficients associated with the domestic and foreign variables, respectively. As the lag orders for these variables, $p_{i}$ and $q_{i}$, are selected on a country-by-country basis, we are explicitly allowing for $\boldsymbol{\Phi}_{i}\left(L, p_{i}\right)$ and $\boldsymbol{\Lambda}_{i}\left(L, q_{i}\right)$ to differ across countries.

The country-specific foreign variables are constructed as cross-sectional averages of the domestic variables using data on bilateral trade as the weights, $w_{i j}$ 


$$
\mathbf{x}_{i t}^{*}=\sum_{j=1}^{N} w_{i j} \mathbf{x}_{j t}
$$

where $j=1,2, \ldots, N, w_{i i}=0$, and $\sum_{j=1}^{N} w_{i j}=1$. For empirical application, the trade weights are computed as 3 -year averages ${ }^{7}$

$$
w_{i j}=\frac{T_{i j, 2007}+T_{i j, 2008}+T_{i j, 2009}}{T_{i, 2007}+T_{i, 2008}+T_{i, 2009}},
$$

where $T_{i j t}$ is the bilateral trade of country $i$ with country $j$ during a given year $t$ and is calculated as the average of exports and imports of country $i$ with $j$, and $T_{i t}=\sum_{j=1}^{N} T_{i j t}$ (the total trade of country $i$ ) for $t=2007,2008$, and 2009, in the case of all countries. ${ }^{8}$

Although estimation is done on a country-by-country basis, the GVAR model is solved for the world as a whole, taking account of the fact that all variables are endogenous to the system as a whole. After estimating each country $\operatorname{VARX} *\left(p_{i}, q_{i}\right)$ model separately, all the $k=\sum_{i=1}^{N} k_{i}$ endogenous variables, collected in the $k \times 1$ vector $\mathbf{x}_{t}=\left(\mathbf{x}_{1 t}^{\prime}, \mathbf{x}_{2 t}^{\prime}, \ldots, \mathbf{x}_{N t}^{\prime}\right)^{\prime}$, need to be solved simultaneously using the link matrix defined in terms of the country-specific weights. To see this, we can write the VARX* model in equation (1) more compactly as

$$
\mathbf{A}_{i}\left(L, p_{i}, q_{i}\right) \mathbf{z}_{i t}=\boldsymbol{\varphi}_{i t},
$$

for $i=1, \ldots, N$, where

$$
\begin{aligned}
\mathbf{A}_{i}\left(L, p_{i}, q_{i}\right) & =\left[\boldsymbol{\Phi}_{i}\left(L, p_{i}\right)-\mathbf{\Lambda}_{i}\left(L, q_{i}\right)\right], \quad \mathbf{z}_{i t}=\left(\mathbf{x}_{i t}^{\prime}, \mathbf{x}_{i t}^{\prime *}\right)^{\prime}, \\
\boldsymbol{\varphi}_{i t} & =\mathbf{a}_{i 0}+\mathbf{a}_{i 1} t+\mathbf{u}_{i t} .
\end{aligned}
$$

Note that given Eq. (2) we can write

$$
\mathbf{z}_{i t}=\mathbf{W}_{i} \mathbf{x}_{t}
$$

where $\mathbf{W}_{i}=\left(\mathbf{W}_{i 1}, \mathbf{W}_{i 2}, \ldots, \mathbf{W}_{i N}\right)$, with $\mathbf{W}_{i i}=0$, is the $\left(k_{i}+k_{i}^{*}\right) \times k$ weight matrix for country $i$ defined by the country-specific weights, $w_{i j}$. Using (6) we can write (4) as

$$
\mathbf{A}_{i}(L, p) \mathbf{W}_{i} \mathbf{x}_{t}=\varphi_{i t},
$$

where $\mathbf{A}_{i}(L, p)$ is constructed from $\mathbf{A}_{i}\left(L, p_{i}, q_{i}\right)$ by setting $p=\max \left(p_{1}, p_{2}, \ldots\right.$, $\left.p_{N}, q_{1}, q_{2}, \ldots, q_{N}\right)$ and augmenting the $p-p_{i}$ or $p-q_{i}$ additional terms in the power

\footnotetext{
7 The main justification for using bilateral trade weights, as opposed to financial weights, is that the former have been shown to be the most important determinant of national business cycle comovements. See, for instance, Baxter and Kouparitsas (2005).

8 As a robustness check, we estimated the model using trade weights averaged over alternative time windows (2005-2007 and 2000-2009) and found the results to be quantitatively similar. See also Cashin et al. (2017b), who demonstrate that the choice of weights is of second-order importance when the underlying variables are sufficiently correlated, and that using trade, financial, or mixed weights produces similar results.
} 
of the lag operator by zeros. Stacking Eq. (7), we obtain the global VAR $(p)$ model in domestic variables only

$$
\mathbf{G}(L, p) \mathbf{x}_{t}=\varphi_{t},
$$

where

$$
\mathbf{G}(L, p)=\left(\begin{array}{c}
\mathbf{A}_{1}(L, p) \mathbf{W}_{1} \\
\mathbf{A}_{2}(L, p) \mathbf{W}_{2} \\
\cdot \\
\cdot \\
\cdot \\
\mathbf{A}_{N}(L, p) \mathbf{W}_{N}
\end{array}\right), \quad \varphi_{t}=\left(\begin{array}{c}
\varphi_{1 t} \\
\varphi_{2 t} \\
\cdot \\
\cdot \\
\cdot \\
\varphi_{N t}
\end{array}\right) .
$$

For an early illustration of the solution of the GVAR model, using a VARX* $(1,1)$ model, see Pesaran (2004), and for an extensive survey of the latest developments in GVAR modeling, both the theoretical foundations of the approach and its numerous empirical applications, see Chudik and Pesaran (2016). The GVAR $(p)$ model in Eq. (8) can be solved recursively and used for a number of purposes, such as forecasting or impulse response analysis.

\subsection{Country-specific VARX* models}

We include as many major oil exporters as possible in our multi-country setup, subject to data availability, together with as many countries in the world to represent the global economy. Thus, our version of the GVAR model covers 50 countries as opposed to the standard 33 country setups used in the literature, see Smith and Galesi (2014), and extends the coverage both in terms of major oil exporters and also by including an important region of the world when it comes to oil supply, the MENA region. ${ }^{9}$

Of the 50 countries included in our sample, 18 are classified as major commodity exporters as primary commodities constitute more than $40 \%$ of their exports (these countries are denoted by * in Table 1). Moreover, 15 are net oil exporters of which 10 are current members of the OPEC (denoted by ${ }^{1}$ in Table 1 ) and one is a former member (Indonesia left OPEC in January 2009). We were not able to include Angola and Iraq, the remaining two OPEC members, due to the lack of sufficiently long time-series data. This was also the case for Russia, the second largest oil exporter in the world, for which quarterly data are not available for the majority of our sample period. ${ }^{10}$ Our sample also includes three OECD oil exporters (Canada, Mexico, and Norway) and the UK, which remained a net oil exporter for the majority of the sample (until 2006), and therefore is treated as an oil exporter when it comes to imposing sign restrictions (see the discussion in Sect. 3.1). These 50 countries together cover over $90 \%$ of world

\footnotetext{
9 For an extensive discussion on the impact of three systemic economies (China, Euro Area, and the US) on the MENA region, see Cashin et al. (2016).

10 Having data over a sufficiently long time period is important when it comes to estimating the GVAROil model, and including Russia would have meant estimating the country-specific VARX* models using significantly less quarterly observations (using 76 quarterly observations rather than 127), making the results much less reliable; see Mohaddes and Pesaran (2016) for an extensive discussion. Nonetheless, we believe that inclusion of Russia in the model would not have a material impact on the transmission of a US supplydriven oil price shock. Though it would matter if we were to study the role of a Russia-induced change in the price of oil-something which is beyond the scope of this paper.
} 
Table 1 Countries and regions in the GVAR model

\begin{tabular}{lll}
\hline Systemic countries & MENA oil exporters & Latin America \\
China & Algeria*12 & Argentina* \\
Euro Area & GCC & Brazil* $^{*}$ \\
Austria & Bahrain*2 & Chile* \\
Belgium & Kuwait*12 & Ecuador*1 \\
Finland & Oman* & Mexico \\
France & Qatar*12 & Peru* \\
Germany & Saudi Arabia*12 & Venezuela*1 \\
Italy & UAE*12 & \\
Netherlands & Iran*1 & Southeast Asia \\
Spain & Libya*12 & Indonesia* \\
India & & Korea \\
Japan & MENA oil importers & Malaysia \\
UK & Egypt*2 & Philippines \\
USA & Jordan & Singapore \\
& Mauritania* & Thailand \\
Rest of advanced economies & Morocco* & \\
Australia & Syria*2 & Rest of the world \\
Canada & Tunisia*2 & Nigeria*1 \\
New Zealand & Turkey & South Africa* \\
Norway* & & \\
Sweden & & \\
Switzerland & & \\
\hline GCC is & & \\
\hline
\end{tabular}

GCC is the Gulf Cooperation Council Countries and MENA refers to the countries in the Middle East and North Africa region. * indicates that the country is a commodity exporter; countries are classified as commodity exporters if primary commodities constitute more than $40 \%$ of their exports. ${ }^{1,2}$ denote countries which are members of the Organization of the Petroleum Exporting Countries (OPEC) and the Organization of Arab Petroleum Exporting Countries (OAPEC), respectively

GDP, $85 \%$ of world oil consumption, and $80 \%$ of world proven oil reserves. Thus, our sample is rather comprehensive.

For empirical applications, we create two regions: one of which comprises the six Gulf Cooperation Council (GCC) countries: Bahrain, Kuwait, Oman, Qatar, Saudi Arabia, and the United Arab Emirates (UAE); and the other is the Euro Area block comprising 8 of the 11 countries that initially joined the euro on January 1, 1999: Austria, Belgium, Finland, France, Germany, Italy, Netherlands, and Spain. The time-series data for the GCC block and the Euro Area block are constructed as cross-sectionally weighted averages of the domestic variables (described in detail below), using purchasing power parity GDP weights, averaged over the 2007-2009 period. Thus, as displayed in Table 1, our model includes 38 country-/region-specific VARX* models.

Making one region out of Bahrain, Kuwait, Oman, Qatar, Saudi Arabia, and the United Arab Emirates is not without economic reasoning. The rationale is that these 
countries have in recent decades implemented a number of policies and initiatives to foster economic and financial integration in the region with a view to establishing a monetary union (loosely based on that of the Euro Area). Abstracting from their level of success with above objectives, the states of the GCC are relatively similar in structure, though in the short term they may face some difficulties in meeting the convergence criteria they have set for economic integration based on those of the European Union (EU). Inflation rates vary significantly across these countries, and fiscal deficits, which have improved since the start of the oil boom in 2003, are about to re-emerge in some countries. However, these economies already peg their currencies to the US dollar, except for Kuwait, which uses a dollar-dominated basket of currencies, and are accustomed to outsourcing their interest rate policy. They also have relatively open capital accounts, and hence, it is reasonable to group these countries as one region. ${ }^{11}$

We specify two different sets of individual country-specific models. The first model is common across all countries, apart from the USA. These 37 VARX* models include a maximum of six domestic variables (depending on whether data on a particular variable is available), or using the same terminology as in equation (1)

$$
\mathbf{x}_{i t}=\left[y_{i t}, \pi_{i t}, e q_{i t}, r_{i t}^{S}, r_{i t}^{L}, e p_{i t}\right]^{\prime},
$$

where $y_{i t}$ is the log of the real gross domestic product at time $t$ for country $i, \pi_{i t}$ is inflation, $e q_{i t}$ is the log of real equity prices, $r_{i t}^{S}\left(r_{i t}^{L}\right)$ is the short-term (long-term) interest rate, and $e p_{i t}$ is the real exchange rate. In addition, all domestic variables, except for that of the real exchange rate, have corresponding foreign variables computed as in Eq. (2)

$$
\mathbf{x}_{i t}^{*}=\left[y_{i t}^{*}, \pi_{i t}^{*}, e q_{i t}^{*}, r_{i t}^{* S}, r_{i t}^{* L}\right]^{\prime} .
$$

Following the GVAR literature, the 38th model (USA) is specified differently, mainly because of the dominance of the USA in the world economy. First, given the importance of US financial variables in the global economy, the US-specific foreign financial variables, $e q_{U S, t}^{*}$ and $r_{U S, t}^{* L}$, are not included in this model. The appropriateness of exclusion of these variables was also confirmed by statistical tests, in which the weak exogeneity assumption was rejected for $e q_{U S, t}^{*}$ and $r_{U S, t}^{* L}$. Second, since $e_{i t}$ is expressed as the domestic currency price of a US dollar, it is by construction determined outside this model. Thus, instead of the real exchange rate, we included $e_{U S, t}^{*}-p_{U S, t}^{*}$ as a weakly exogenous foreign variable in the US model. ${ }^{12}$

\subsection{The global oil market}

To consider the macroeconomic effects of the US oil revolution, we also need to include nominal oil prices in US dollars in the country-specific VARX* models. If we follow the literature, we would include log oil prices, $p_{t}^{o}$, as an endogenous variable in the US VARX* model and as a weakly exogenous variable in all other countries. See, for

11 See Mohaddes and Williams (2013) for more details.

12 Weak exogeneity test results for all countries and variables are available upon request. 

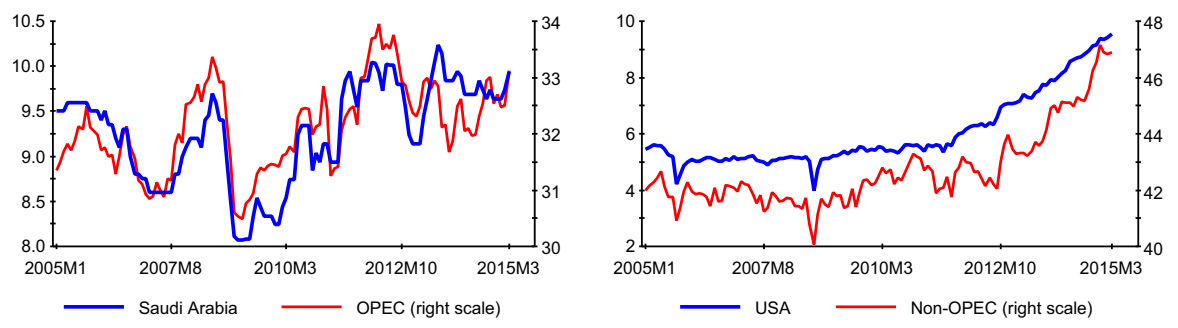

Fig. 2 Oil production in million barrels per day, 2005M1-2015M3. Source: U.S. Energy Information Administration Monthly Energy Review

example, Cashin et al. (2014) and Chudik and Pesaran (2016). The main justification for this approach is that USA is the world's largest oil consumer and a demand-side driver of the price of oil. However, it seems more appropriate for oil prices to be determined in global commodity markets rather in the US model alone, given that oil prices are also affected by, for instance, any disruptions to oil supply in the Middle East. Therefore, in contrast to the GVAR literature, we model the oil price equation separately and then introduce $p_{t}^{o}$ as a weakly exogenous variable in all countries (including the USA), thereby allowing for both demand and supply conditions to influence the price of oil directly rather than using the US model as a transmission mechanism for the global economic conditions to the price of oil. ${ }^{13}$

To add oil prices to the conditional country models, we simply augment the VARX* models (1) by $p_{t}^{o}$ and its lag values

$$
\boldsymbol{\Phi}_{i}\left(L, p_{i}\right) \mathbf{x}_{i t}=\mathbf{a}_{i 0}+\mathbf{a}_{i 1} t+\mathbf{\Lambda}_{i}\left(L, q_{i}\right) \mathbf{x}_{i t}^{*}+\Upsilon_{i}\left(L, s_{i}\right) p_{t}^{o}+\mathbf{u}_{i t}
$$

where $\Upsilon_{i}\left(L, s_{i}\right)=\sum_{i=0}^{s_{i}} \Upsilon_{i} L^{i}$ is the lag polynomial of the coefficients associated with oil prices, see Chudik and Pesaran (2013) for more details. Here, $p_{t}^{o}$ can be treated (and tested) as weakly exogenous for the purpose of estimation and the marginal model for the oil price equation can be estimated with or without feedback effects from $\mathbf{x}_{t}$. We incorporate the global oil market within the GVAR framework, by introducing an oil price equation

$$
p_{t}^{o}=c_{p}+\sum_{\ell=1}^{m_{p}} \alpha_{\ell} p_{t-\ell}^{o}+\sum_{\ell=1}^{m_{y}} \beta_{\ell} y_{t-\ell}+\sum_{\ell=1}^{m_{q}} \gamma_{\ell} q_{t-\ell}^{o}+u_{t}^{o}
$$

which is a standard autoregressive distributed lag, $\operatorname{ARDL}\left(m_{p^{o}}, m_{y}, m_{q^{o}}\right)$, model in oil prices, world real income $\left(y_{t}\right)$ to proxy for global demand and world oil supplies $\left(q_{t}^{o}\right)$, with all variables being in logs. Conditional (12) and marginal models (13) can be combined and solved as a complete GVAR model as explained earlier (see Sect. 2.1).

13 See also Cashin et al. (2017a) and Mohaddes and Pesaran (2016) for a similar approach. 
To take into account developments in the world economy, the oil price equation includes a measure of global output, $y_{t}$, calculated as

$$
y_{t}=\sum_{j=1}^{N} w_{j}^{P P P} y_{j t},
$$

where $y_{j t}$ is the $\log$ of real GDP of country $j$ at time $t, j=1,2, \ldots, N, w_{j}^{P P P}$ is the PPP GDP weights of country $j$, and $\sum_{j=1}^{N} w_{j}^{P P P}=1$. We compute $w_{j}^{P P P}$ as a three-year average to reduce the impact of individual yearly movements on the weights

$$
w_{j}^{P P P}=\frac{G D P_{j, 2007}^{P P P}+G D P_{j, 2008}^{P P P}+G D P_{j, 2009}^{P P P}}{G D P_{2007}^{P P P}+G D P_{2008}^{P P P}+G D P_{2009}^{P P P}},
$$

where $G D P_{j t}^{P P P}$ is the GDP of country $j$ converted to international dollars using purchasing power parity rates during a given year $t$ and $G D P_{t}^{P P P}=$ $\sum_{j=1}^{N} G D P_{j t}^{P P P}$.

To capture global oil supply conditions, we have also included a measure for the quantity of oil produced in the world in Eq. (13). A key question is how should $q_{t}^{o}$ be included in our country-specific models? Looking at the 12 Organization of the Petroleum Exporting Countries (OPEC), of which some members are the largest oil producers in the world, we know that the amount of oil they produce in any given day plays a significant role in the global oil markets; however, they differ considerably from each other in terms of how much oil they produce (and export) and their level of proven oil reserves. Within OPEC, Saudi Arabia has a unique position as it is not only the largest oil producer and exporter in the world, but it also has the largest spare capacity and as such is often seen as a global swing producer. For example, in September 1985, Saudi production was increased from 2 million barrels per day (mbd) to $4.7 \mathrm{mbd}$ (causing oil prices to drop from $\$ 57.61$ to $\$ 29.62$ in real terms) ${ }^{14}$ and more recently following the US and the EU sanctions on Iran, Saudi Arabia has increased its production to stabilize the oil market. In fact, as is shown in Fig. 2 the relationship between Saudi Arabian oil production and total OPEC oil production is a very close one. In our application, Saudi Arabia and the other five GCC countries (Bahrain, Kuwait, Oman, Qatar, and the UAE) are grouped as one region, with this region then playing an important role when it comes to world oil supply. ${ }^{15}$ Not only do these six countries produce more than $22 \%$ of world oil and export around $30 \%$ of the world total, the six GCC countries also possess $36.3 \%$ of the world's proven oil reserves. ${ }^{16}$ Therefore, given the status of the GCC countries with regards to OPEC oil supply, we include log of OPEC oil production, as an endogenous variable in the GCC block.

\footnotetext{
14 See Mohaddes (2013) for more details.

15 Although Bahrain and Oman are not OPEC members, we include them in the OPEC block as we treat the GCC countries as a region. Note that using PPP GDP weights, Bahrain and Oman are less than $8 \%$ of the total GDP of the GCC.

16 Oil reserve and production data are from the British Petroleum Statistical Review of World Energy and oil export data are from the OPEC Annual Statistical Bulletin.
} 
We now turn to non-OPEC oil supply. As Fig. 2 shows, the increase in non-OPEC production over the last decade is more or less the result of the oil revolution which has increased US production by $50 \%$ (from approximately 6-9 mbd). The recent technological advancements have not only reduced the costs associated with the production of tight oil, but also made the extraction resemble a manufacturing process in which the quantity produced can be altered in response to price changes with relative ease, which is not the case for conventional oil extraction which requires large capital expenditure and lead times. In other words, US oil production can play a significant role in balancing global demand and supply. Given the developments in the last decade, we model non-OPEC oil production within the US model.

\section{Empirical results}

We obtain data on $\mathbf{x}_{i t}$ for 33 out of the 50 countries included in our sample (see Table 1) from Smith and Galesi (2014). Data for the remaining 17 countries: Algeria, Bahrain, Ecuador, Egypt, Iran, Jordan, Kuwait, Libya, Mauritania, Morocco, Nigeria, Oman, Qatar, Syria, Tunisia, Venezuela, and the UAE are from Cashin et al. (2016). Oil price data (monthly average of Brent crude series) are also from the GVAR Web site, while data on oil production are from the U.S. Energy Information Administration Monthly Energy Review. ${ }^{17}$

We use quarterly observations over the period 1979Q2-2011Q2 to estimate the 38 country-specific VARX* $\left(p_{i}, q_{i}\right)$ models. However, prior to estimation, we determine the lag orders of the domestic and foreign variables, $p_{i}$ and $q_{i}$. For this purpose, we use the Akaike information criterion (AIC) applied to the underlying unrestricted VARX* models. Given data constraints, we set the maximum lag orders to $p_{\max }=q_{\max }=2$. The selected VARX* orders are reported in Table 2. Moreover, for the lag order of the $\operatorname{ARDL}\left(m_{p^{o}}, m_{y}, m_{q^{o}}\right)$ model in oil prices, world real income, and world oil supplies, AIC selects $m_{p^{o}}=m_{y}=m_{q^{o}}=2$.

Having established the lag order of the 38 VARX* models, we proceed to determine the number of long-run relations. Cointegration tests with the null hypothesis of no cointegration, one cointegrating relation, and so on are carried out using Johansen's maximal eigenvalue and trace statistics as developed in Pesaran et al. (2000) for models with weakly exogenous $I$ (1) regressors, unrestricted intercepts, and restricted trend coefficients. We choose the number of cointegrating relations $\left(r_{i}\right)$ using the trace test statistics based on the 5\% critical values from MacKinnon (1991). We then consider the effects of system-wide shocks on the exactly identified cointegrating vectors using persistence profiles developed by Lee and Pesaran (1993) and Pesaran and Shin (1996). On impact the persistence profiles (PPs) are normalized to take the value of unity, but the rate at which they tend to zero provides information on the speed with which equi-

\footnotetext{
17 The rapid expansion of North American tight oil production and the accumulation of an oil surplus in the US Midwest have led to a segmentation of the North American crude oil market from the global market (Alquist and Gunette 2014). This segmentation has contributed to the increasing divergence between the West Texas Intermediate (WTI) and Brent crude oil prices recently. Nonetheless, using WTI instead of Brent crude oil prices in our analysis does not alter the results presented in this paper.
} 
Table 2 Lag orders of the country-specific VARX* $(\mathrm{p}, \mathrm{q})$ models together with the number of cointegrating relations (r)

\begin{tabular}{|c|c|c|c|c|c|c|c|}
\hline \multirow[t]{2}{*}{ Country } & \multicolumn{2}{|c|}{ VARX* order } & \multirow{2}{*}{$\begin{array}{l}\text { Cointegrating } \\
\text { relations }\left(\widehat{r}_{i}\right)\end{array}$} & \multirow[t]{2}{*}{ Country } & \multicolumn{2}{|c|}{ VARX* Order } & \multirow{2}{*}{$\begin{array}{l}\text { Cointegrating } \\
\text { relations }\left(\widehat{r}_{i}\right)\end{array}$} \\
\hline & $\widehat{p}_{i}$ & $\widehat{q}_{i}$ & & & $\widehat{p}_{i}$ & $\widehat{q}_{i}$ & \\
\hline Algeria & 2 & 2 & 1 & Morocco & 1 & 1 & 2 \\
\hline Argentina & 2 & 2 & 2 & Mauritania & 2 & 1 & 1 \\
\hline Australia & 1 & 1 & 4 & Mexico & 1 & 2 & 2 \\
\hline Brazil & 2 & 2 & 2 & Nigeria & 2 & 1 & 2 \\
\hline Canada & 1 & 2 & 4 & Norway & 2 & 1 & 2 \\
\hline China & 1 & 1 & 1 & New Zealand & 2 & 2 & 3 \\
\hline Chile & 2 & 2 & 2 & Peru & 2 & 2 & 2 \\
\hline Ecuador & 2 & 1 & 1 & Philippines & 2 & 1 & 2 \\
\hline Egypt & 1 & 1 & 2 & South Africa & 2 & 1 & 2 \\
\hline Euro Area & 1 & 1 & 3 & Singapore & 2 & 1 & 3 \\
\hline GCC & 2 & 1 & 3 & Sweden & 2 & 1 & 3 \\
\hline India & 2 & 1 & 2 & Switzerland & 1 & 1 & 3 \\
\hline Indonesia & 2 & 2 & 3 & Syria & 2 & 2 & 1 \\
\hline Iran & 1 & 2 & 2 & Thailand & 2 & 1 & 2 \\
\hline Japan & 2 & 2 & 3 & Tunisia & 2 & 1 & 2 \\
\hline Jordan & 2 & 1 & 1 & Turkey & 2 & 2 & 1 \\
\hline Korea & 2 & 2 & 2 & UK & 1 & 2 & 3 \\
\hline Libya & 2 & 1 & 1 & USA & 2 & 1 & 3 \\
\hline Malaysia & 1 & 1 & 1 & Venezuela & 2 & 1 & 1 \\
\hline
\end{tabular}

Notes: $\widehat{p}_{i}$ and $\widehat{q}_{i}$ denote the estimated lag orders for the domestic and foreign variables, respectively, selected by the Akaike information criterion, with the maximum lag orders set to 2 . The number of cointegrating relations $\left(\hat{r}_{i}\right)$ is selected using the trace test statistics based on the 5\% critical values from MacKinnon (1991) for all countries except for Algeria, Canada, China, Iran, Korea, and Tunisia for which we reduced $r_{i}$ below that suggested by the trace statistic to ensure the stability of the global model. Source: Authors' estimations

librium correction takes place in response to shocks. The PPs could initially overshoot, thus exceeding unity, but must eventually tend to zero if the vector under consideration is indeed cointegrated. In our analysis of the PPs, we noticed that the speed of convergence was very slow for Algeria, Canada, China, Iran, Korea, and Tunisia, and for a few of them, the system-wide shocks never really died out, so we reduced $r_{i}$ by one for each country, except for Korea for which we reduced $\widehat{r}_{i}$ from 5 to 2 , resulting in well-behaved PPs overall. The final selection of the number of cointegrating relations is reported in Table 2.

\subsection{Identification strategy}

To separate oil supply shocks due to the US oil revolution from other supply shocks, such as disruptions caused by geopolitical tensions in the Middle East, and oil demand shocks in general, we rely on two sets of identifying restrictions within our GVAR-Oil 

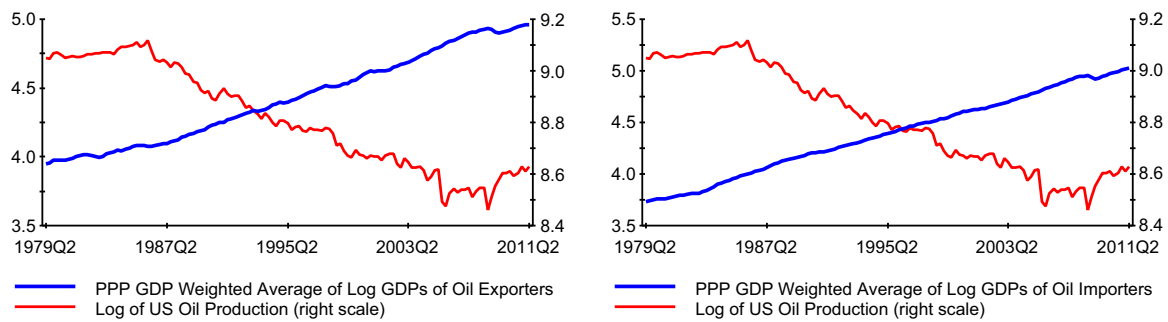

Fig. 3 Weighted average of the GDPs of oil exporters and importers and US oil production, 1979Q22011Q2. Source: Authors' calculations based on data from U.S. Energy Information Administration Monthly Energy Review, Smith and Galesi (2014) and Cashin et al. (2016)

framework: (a) dynamic sign restrictions and (b) cross-country sign restrictions arising from the global dimension of the GVAR-Oil model. Regarding these two conditions, we require the oil revolution to be associated with: (i) a decrease in oil prices; (ii) an increase in the level of US oil production; (iii) a constant OPEC oil production; and (iv) an increase in the sum of real GDPs across all major oil importers in our sample. ${ }^{18}$ Since the effect of a positive oil supply shock on the level of GDP of major oil and commodity exporters (for which primary commodities constitute more than $40 \%$ of their exports) in our sample is ambiguous, we do not impose any dynamic sign restrictions on them, see Fig. 3. Moreover, we do not impose any restriction on the GDP for Jordan as Mohaddes and Raissi (2013) show that for an oil-importing but labor-exporting small open economy which receives large (and stable) inflows of external income (the sum of FDI, remittances, and grants) from oil-rich countries, the impact of oil shocks on the economy's macroeconomic variables can be very similar to those of the oil exporters from which it receives these large income flows. Note that other than $y_{i t}$ we do not impose any restrictions on the remaining variables in $\mathbf{x}_{i t}$, that is, inflation, the real exchange rate, equity prices, and both the short- and long-term interest rates.

We impose these sign restrictions, (i)-(iv), to hold for one year after the shock to allow for sluggish responses of quantity measures (oil production and real GDPs). This scheme is effective in identifying oil supply disturbances as other shocks cannot move oil prices, oil production levels, and real GDPs (across all oil-importing countries) in opposite directions. We should stress that while the quantity restrictions help with the identification of supply shocks, the global dimension of the GVAR model offers an intuitive way of imposing a large number of additional sign restrictions and can therefore greatly reduce the number of admissible models to better identify the shock. ${ }^{19}$ Specifically, condition (iv) imposes that the cumulated sum of the relevant individual

18 Instead of dry cargo index of Kilian (2009), we rely on an alternative measure of global real economic activity in our GVAR-Oil model. Note that we are not imposing any restrictions on GDPs of major oilimporting countries individually, but collectively (i.e., sum of GDPs of major oil importers being positive). There could be cases in which the GDP of an individual country falls after the shock.

19 We also re-estimated a GVAR model with sign restrictions on (i), (ii), and (iii) only and found the impulse responses to be very similar (in terms of both shape and magnitude) to those reported with additional sign restrictions on the sum of GDPs of major oil importers, (iv). The extra restrictions on the sum of GDPs help reduce the number of admissible models-i.e., with restrictions (i), (ii), and (iii) only, out of 10,000 
country outputs is positive faced with a US oil supply shock. ${ }^{20}$ Intuitively, this positive oil supply shock is perceived to be a tax reduction on oil consumers (with a high propensity to consume) at the expense of oil producers (with a lower propensity to consume) and is associated with an increase in global aggregate demand (hence the cross-country restrictions).

Given these identifying restrictions, the implementation procedure is as follows. Let $\mathbf{v}_{i t}$ denote the structural VARX* model innovations given by

$$
\mathbf{v}_{i t}=\tilde{\mathbf{P}}_{i} \mathbf{u}_{i t},
$$

where $\tilde{\mathbf{P}}_{i}$ is a $k_{i} \times k_{i}$ matrix of coefficients to be identified. We carry out a Cholesky decomposition of the covariance matrix of the vector of residuals $\mathbf{u}_{i t}$ for each country model $i(=1, \ldots, N)$ to obtain the lower triangular matrix $\mathbf{P}_{i}$ that satisfies $\boldsymbol{\Sigma}_{\mathbf{v}_{i}}=\mathbf{P}_{i} \mathbf{P}_{i}^{\prime}$. However, for any orthogonal $k_{i} \times k_{i}$ matrix $\mathbf{Q}_{i}$, the matrix $\tilde{\mathbf{P}}_{i}=\mathbf{P}_{i} \mathbf{Q}_{i}$ also satisfies $\boldsymbol{\Sigma}_{\mathbf{v}_{i}}=\tilde{\mathbf{P}}_{i} \tilde{\mathbf{P}}_{i}^{\prime}$. To examine a wide range of possible solutions for $\tilde{\mathbf{P}}_{i}$ and construct a set of admissible models, we repeatedly draw at random from the orthogonal matrices $\mathbf{Q}_{i}$ and discard candidate solutions for $\tilde{\mathbf{P}}_{i}$ that do not satisfy a set of a priori sign and quantity restrictions on the implied impulse responses functions. These rotations are based on the QR decomposition.

More compactly, we construct the $k \times k$ matrix $\tilde{\mathbf{P}}$ as

$$
\tilde{\mathbf{P}}=\left(\begin{array}{ccccc}
\tilde{\mathbf{P}}_{1} & \mathbf{0} & \ldots & \ldots & \mathbf{0} \\
\mathbf{0} & \ddots & & & \vdots \\
\vdots & & \tilde{\mathbf{P}}_{i} & & \vdots \\
\vdots & & & \ddots & \mathbf{0} \\
\mathbf{0} & \ldots & \ldots & \mathbf{0} & \tilde{\mathbf{P}}_{N}
\end{array}\right),
$$

which can be used to obtain the impulse responses of all endogenous variables in the GVAR-Oil model to shocks to the error terms $\mathbf{v}_{t}=\left(\mathbf{v}_{1 t}^{\prime}, \ldots, \mathbf{v}_{i t}^{\prime}, \ldots, \mathbf{v}_{N t}^{\prime}\right)^{\prime}=\tilde{\mathbf{P}} \mathbf{u}_{t}$. We draw 10, 000 times and only retain those valid rotations that satisfy our set of $a$ priori restrictions. ${ }^{21}$

Since there are a few impulse responses that satisfy our postulated identifying restrictions, we summarize them by reporting a central tendency and the 5th and 95th percentiles as measures of the spread of responses. Although the remaining modelsafter imposing identifying restrictions (i)-(iv) — imply qualitatively and sometimes quantitatively similar responses, the central tendency measure (i.e., median) for

Footnote 19 continued

random draws of the rotation matrix, we achieve 6096 successful draws. Imposing restriction (iv) reduces the number of admissible models further to 797. These results are not reported in the paper but are available upon request.

20 We also considered a cumulated weighted average of the outputs, using PPP GDP weights, and obtained very similar results. We will thus focus on the results using the simple cumulated sum of the output responses in the remainder of the paper.

21 See Chudik and Fratzscher (2011) for an application of generalized impulse response functions (GIRFs) for structural impulse response analysis. 
impulse responses of different variables (across the 38 countries/regions) may come from different impulse vectors. We therefore follow Fry and Pagan (2011) and report a single model whose impulse responses are as close to the median values of the impulse vector as possible (this is called the median target). It is important to recognize that the distribution here is across different models and it has nothing to do with sampling uncertainty.

\subsection{The macroeconomic effects of the US oil revolution}

Figures 4, 5 and 6 show the estimated median (blue solid) and the median target (black long-dashed) impulse responses (for up to ten years) of key macroeconomic variables of oil exporters and oil-importing countries to a supply-driven oil price shock (emanating from the oil revolution in the USA), together with the 5th and 95th percentile error bands. ${ }^{22}$ The economic consequences of a positive oil supply shock in the USA, equivalent to a 10-12\% fall in the oil prices per quarter, are very different for oil-importing countries compared to energy exporters. With regard to real output, following the US oil supply shock, Euro Area and the USA (two major energy-importing countries) experience a long-lived boost to economic activity- $0.56 \%$ and $0.60 \%$, respectively — while similar responses are observed for the UK (a former oil exporter) and other advanced countries, being on average $0.57 \%$ and $0.42 \%$, respectively. ${ }^{23}$

Our framework takes into account not only the direct exposure of countries to the oil shock but also the indirect effects through secondary or tertiary channels. For instance, as a result of the dominance of the US in the world economy, any increase (or decrease) in economic activity in this country can bring about positive (or negative) spillovers to other economies, as the recent global economic crisis has shown. More generally, the history of past US recessions usually coincides with significant reductions in global growth. Furthermore, the continuing dominance of US debt and equity markets, backed by the still-strong global role of the US dollar, is also playing an important role. This is clearly illustrated in Fig. 4, where what was initially an increase in domestic output due to lower oil prices, translates into a pickup in economic activity even in the medium term due to spillovers through trade and financial channels. However, these spillovers do vary greatly from country to country and depend on, for instance, a particular country's trade exposure to the US or the other advanced economies.

The GDP impact is also positive for most Asian countries (for instance, the South East Asia region experiences on average a long-run boost of $0.71 \%$ ) apart from China where the median target response is negative initially, but becomes positive and around $0.04 \%$ over the long term. However, given China's heavy dependence on coal, as opposed to oil, for its energy consumption needs and the composition of its export basket, this result might not be that surprising after all. The USA (Euro Area) met 36\% $(38 \%)$ and $20 \%(13 \%)$ of its primary energy needs from oil and coal sources in 2014 , respectively. In contrast, coal provided over $66 \%$ of China's primary energy needs in 2014, while oil amounted to less than $18 \%$ of the total. In fact, China accounts for

\footnotetext{
22 We attach more weight to median target responses as we would like to track a single model at all times.

23 Note that there is a permanent level effect on GDP of almost all countries in our sample and a temporary growth effect on their real GDP growth.
} 


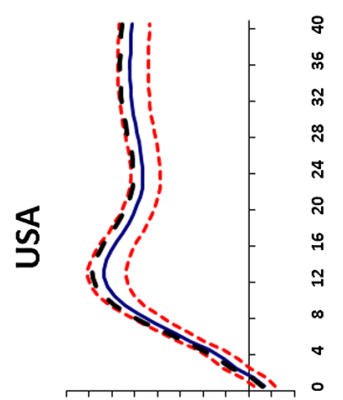

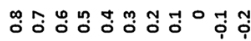

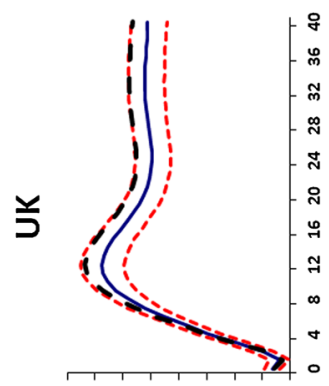

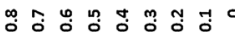
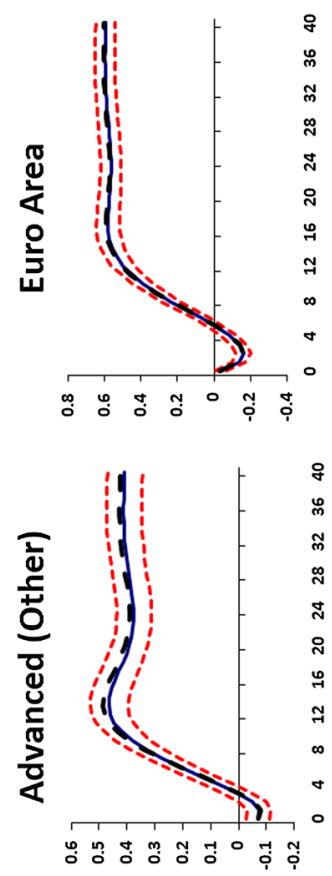
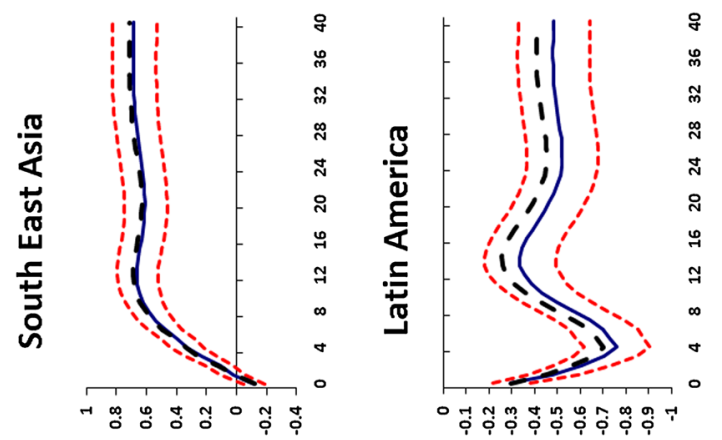

글 $\cong$

苂

ڤ.

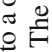

峁

के

D

常

害豆

Эิ

卷

음
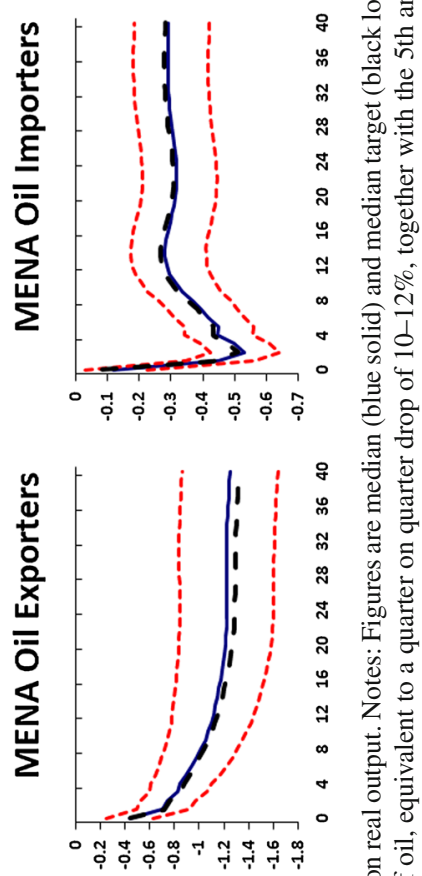

쿠

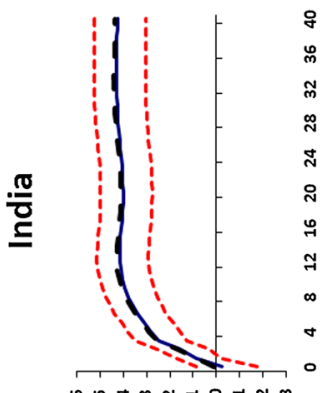

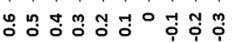
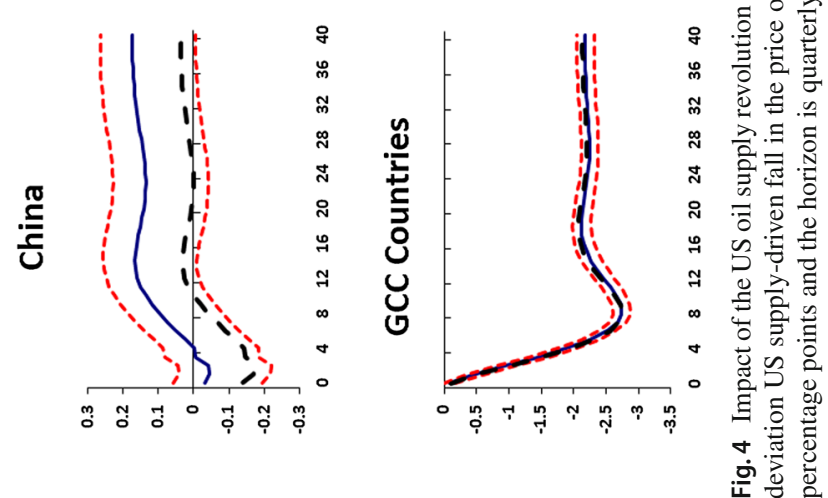

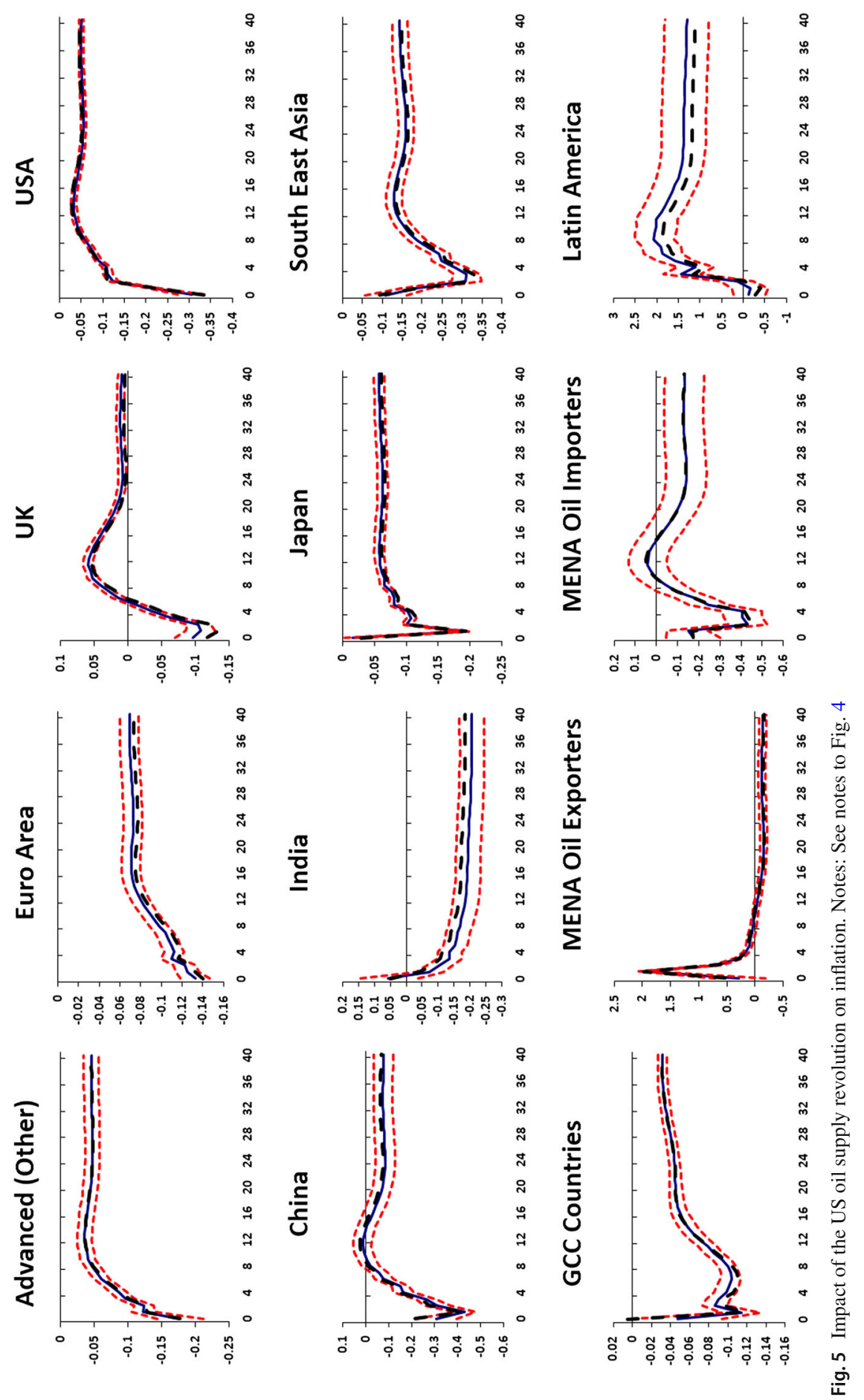

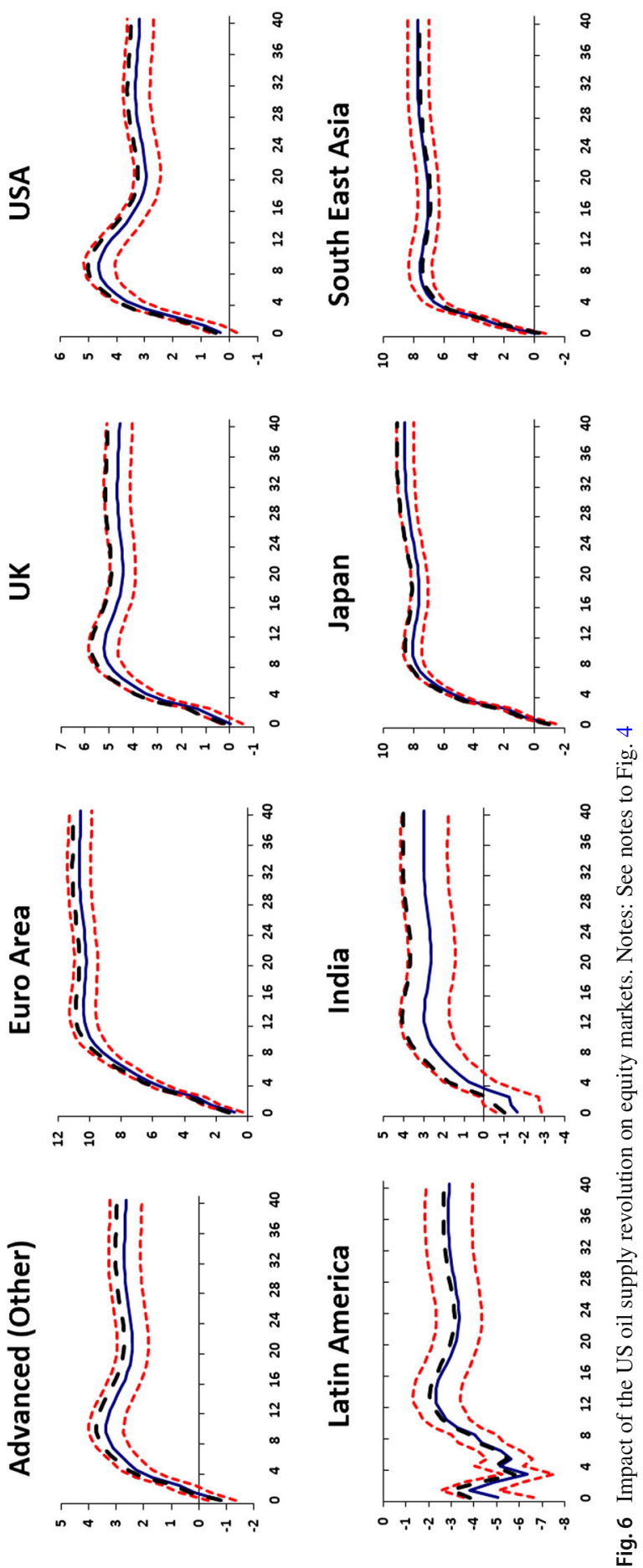
just over half of global coal consumption, and its coal use has almost tripled since 2000 (see British Petroleum's Statistical Review of World Energy). Considering the dominance of coal (rather than oil) in the Chinese economy, and given that most of its coal consumption (well over 90\%) is met by domestic production, oil supply shocks will have relatively less of an impact on the Chinese economy.

Turning to the commodity exporters in our sample, it appears that an oil supply shock in the US creates a slowdown in economic activity in these regions (GCC, MENA, and Latin America) to varying degrees (given lower commodity prices) - the extent of which, at least in the short-term, depends on the size of their buffers and availability of financing. The largest effects are in the GCC and the other MENA oil exporters of $-2.14 \%$ and $-1.32 \%$ with the effects in Latin America being on average much smaller at $-0.41 \%$. MENA oil importers also experience an economic slowdown of $0.28 \%$ on average following a US oil supply shock given their economic ties with oil exporters in the region. For example, remittances from Jordanians working in the region are an important source of national income (equivalent to 15-20\% of GDP); the Persian Gulf region is the primary destination for Jordanian exports and, in turn, supplies most of its energy requirements; furthermore, the country receives substantial grants and FDI from other states in the region, see Mohaddes and Raissi (2013). Given these linkages, it is no surprise that any slowdown in the GCC region (due to lower oil prices) would adversely affect the Jordanian economy, but also through similar channels other MENA oil importers in general (See Sect. 4).

Looking at the GDP responses from a global perspective, our results suggest that as a result of the US oil revolution, with oil prices falling by about $10-12 \%$ below their pre-shock levels per quarter, and a larger fall at peak (i.e., after one year), global growth increases by $0.16-0.37$ percentage points in the medium term. ${ }^{24}$ In response to lower supply-driven oil prices, we would expect the increase in spending by oil importers to exceed the decline in expenditure by oil exporters given their different marginal propensities to consume/invest. See also Arezki and Blanchard (2014); Baffes et al. (2015); Husain et al. (2015); and Mohaddes and Pesaran (2017) who obtain very similar magnitudes. 25

Following an oil supply shock in the USA, we also find strong disinflation pressures on energy-importing countries in our sample (advanced countries, China, India, South East Asia, and MENA oil importers), with the peak responses ranging between 10 and 50 basis points (see Fig. 5). On impact, inflation falls in all of these oil-importing countries but the persistence of the responses changes with the magnitude of secondround effects, and the stance of monetary policy. The different responses of MENA

24 The global growth effects are calculated from the individual country responses aggregated using PPP GDP weights.

25 Ex-post the boost from lower oil prices since mid-2014 has been offset by an adjustment to lower medium-term growth in most major economies due to idiosyncratic factors. For example, the rebalancing of the Chinese economy from an investment-led growth model to a consumption-driven one, and surges in global financial market volatility have adversely affected an already weak global economic recovery. Cashin et al. (2017b) illustrate that a sharp increase in global financial market volatility could translate into (i) a short-run lower overall world economic growth of around 0.29 percentage points, (ii) lower global equity prices and long-term interest rates, and (iii) significant negative spillovers to emerging market economies (operating through trade and financial linkages). Moreover, they show that following a permanent one percent fall in Chinese GDP, global growth reduces by 0.23 percentage points in the long run. 
oil exporters and Latin American countries are probably driven by movements of the real exchange rate in these economies. The real exchange rate tends to depreciate in these countries, limiting the pass-through effect of lower international oil prices to domestic markets (and inflation).

Furthermore, in all oil-importing countries/regions, equity prices rise following a positive oil supply shock in the US (see Fig. 6). As shown in the equity pricing model of Huang et al. (1996), the equity price equals the expected present discounted value of future cash flows. Since a lower expected inflation reduces the discount rate, a fall in oil price has a positive impact on stock market returns. The positive effect of falling oil prices on stock markets in net oil importers has also been supported by a number of other researches, including Cheung and Ng (1998), Sadorsky (1999) and Park and Ratti (2008).

\section{Focusing on the MENA region}

The results in Sect. 3.2, and Fig. 4 in particular, indicate that the US oil revolution, and the resulting lower oil prices, will likely have a negative growth impact on Middle East and North Africa (MENA) region for both primary commodity exporters and importers. This section investigates in greater detail the macroeconomic implications of the US oil supply revolution, in terms of its real GDP effects, on individual countries in the MENA region over the short and long term. Note that the resulting low oil price environment has also political economy implications. For instance, Elbadawi (2015) argues that a negative and sustained oil price shock, by reducing oil rents per capita, could weaken the government's effectiveness in managing the economy and maintaining civil peace (making the ruling elite more vulnerable to popular uprisings), thereby changing the developmental and sustainable political equilibrium in the GCC countries. While such political economy considerations are important, they are beyond the scope of this paper and will not be tested empirically.

The median target impulse responses in Fig. 7 show that Syria, the GCC, and Iran face a long-lasting fall in their real output (more than $-2 \%$ over the long run) following a positive US oil supply shock as lower oil prices weaken the external and fiscal balances in these countries. For Algeria, an OPEC member, the median target response is negative for the first 14 quarters before stabilizing around zero over the long run. While buffers and available financing allow most oil exporters in the region to avoid sharp cuts in government spending in the near term (limiting the impact on short-term investment and growth), the long-term impact depends on their medium-term fiscal plans and capital spending. Table 3 shows that the fiscal break-even price for all major oil exporters in 2015, except Kuwait, was substantially above \$56.25-the average Brent spot price between January and August 2015.

For most oil importers in the MENA region, gains from lower oil prices are offset by a decline in external demand/financing by oil exporters over the medium term given the strong linkages between the two groups through trade, remittances, tourism, foreign direct investment, and grants. The resulting estimated long-run negative growth 


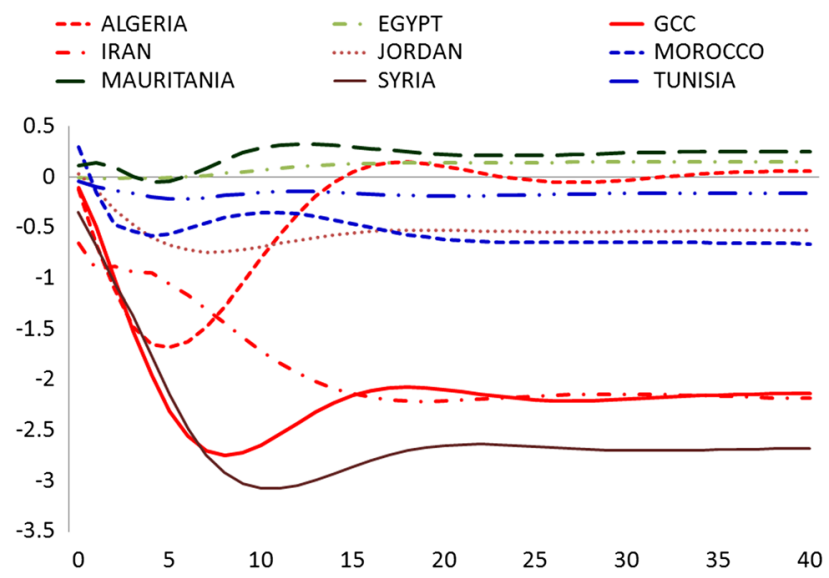

Fig. 7 Impact of the US oil supply revolution on real output in the MENA region. Notes: Figures are median target impulse responses to a one standard deviation US supply-driven fall in the price of oil, equivalent to a quarter on quarter drop of $10-12 \%$. The impact is in percentage points and the horizon is quarterly

Table 3 Fiscal break-even prices for major oil exporters in 2015 (US dollars/barrel). Source: International Monetary Fund and Deutsche Bank

\begin{tabular}{llllll}
\hline Country & $\begin{array}{l}\text { Break-even } \\
\text { prices }\end{array}$ & Country & $\begin{array}{l}\text { Break-even } \\
\text { prices }\end{array}$ & Country & $\begin{array}{l}\text { Break-even } \\
\text { prices }\end{array}$ \\
\hline Algeria & $\$ 111.10$ & Libya & $\$ 215.00$ & Saudi Arabia & $\$ 103.00$ \\
Iran & $\$ 92.50$ & Nigeria & $\$ 87.90$ & UAE & $\$ 73.10$ \\
Iraq & $\$ 70.90$ & Qatar & $\$ 59.10$ & Venezuela & $\$ 89.00$ \\
Kuwait & $\$ 47.10$ & Russia & $\$ 78.00$ & & \\
\hline
\end{tabular}

effects on these countries, although being non-trivial, are much smaller than those on oil exporters - about $-0.5 \%,-0.7 \%$, and $-0.2 \%$ for Jordan, Morocco, and Tunisia, respectively. For Egypt (despite having a relatively large subsidy bill) and Mauritania, the median target responses are positive and about $0.2 \%$ in the medium term. In general, low pass-through from global oil prices to domestic fuel prices limits the impact on disposable income of consumers and profit margins of firms in MENA oil importers and therefore reduces the direct positive impact on economic growth in these countries. The next two subsections discuss the main channels through which long-term growth is being affected by sustained lower commodity prices for major oil exporters as well as select oil importers in the region.

\subsection{A long-run structural model for oil exporters}

Given that oil exporters in our sample (except for Saudi Arabia) are producing at (or near) capacity, they cannot readily increase their production levels in response to lower oil prices to offset the substantial drop in oil revenues following the US oil supply revolution. Even if they were able to increase production, this would only lead to an 


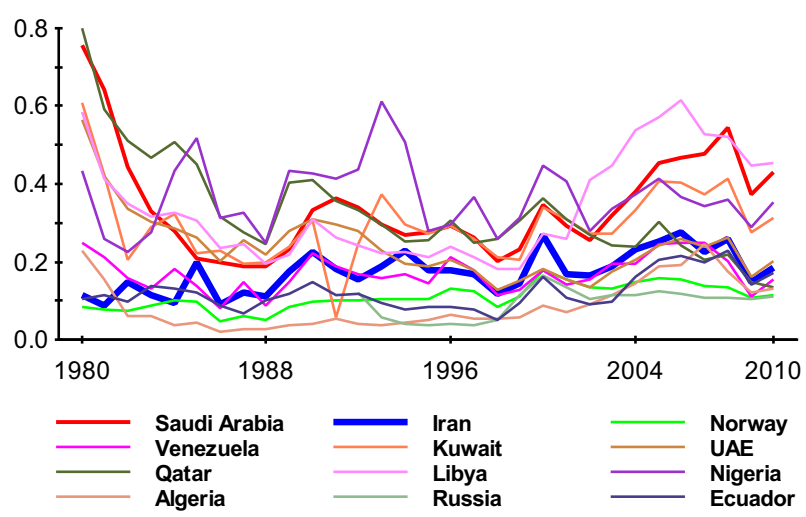

Fig. 8 Ratio of oil export revenues to real output across oil exporters, 1980-2010. Source: British Petroleum Statistical Review of World Energy, OPEC Annual Statistical Bulletin, and IMF International Financial Statistics

increase in global supply, which would in turn depress prices even further, at least in the short run and until current projects from high-cost fields are completed. The question is whether the long-run growth effects of sustained lower oil revenues for major oil exporters can be modeled and empirically tested at the country level and based on a growth theory. If so this would allow one to explore the channels through which the fall in oil revenue affects these economies. Unfortunately, most macroeconomic analyses of oil revenues/shocks tend to take a short-term perspective. They usually focus on the effects of oil revenues on the real exchange rate (Dutch disease) and government budget expansion, thus failing to consider their effects on long-run growth.

This approach makes sense for countries with a limited amount of oil reserves and those facing temporary shocks, but not for major oil- exporting countries such as Iran, Kuwait, and Saudi Arabia for which oil income should be treated more as a part of the steady-state growth outcome and not as a transient state. While it is clear that the oil and gas reserves will be exhausted eventually, this is likely to take place over a relatively long period. Figure 8 shows that most OPEC members such as Algeria, Iran, Kuwait, Nigeria, Saudi Arabia, United Arab Emirates, and Venezuela, and a few countries outside OPEC such as Norway and Russia have similar oil income-to-GDP ratios that have remained relatively stable. ${ }^{26}$

Given that there is little evidence to suggest that for the MENA oil-exporting economies oil income will be diminishing any time soon and the fact that their oil income-to-output ratio is expected to remain high over a prolonged period, we can utilize the empirical growth model for major oil-exporting countries recently developed in Esfahani et al. (2014), to empirically investigate the direct effect of a fall in oil revenue for these economies. More specifically, by extending the stochastic growth model developed in Binder and Pesaran (1999) and allowing for the possibility that a certain fraction of oil revenues is invested in the domestic economy via the capital accumulation channel, Esfahani et al. (2014) show that the long-run output equation

\footnotetext{
26 See Esfahani et al. (2013) and Mohaddes and Pesaran (2014) for an extensive discussion.
} 
for major oil exporters is given by

$$
y_{i t}-\psi_{i 1} y_{i t}^{*}=\psi_{i 2}\left(e_{i t}-p_{i t}\right)+\psi_{i 3} o_{i t}+c_{i y}+\gamma_{i y} t+\xi_{i y, t},
$$

where $o_{i t}$ is oil revenue in US dollars for country $i\left(o_{i t}=q_{i t}^{o} \times p_{t}^{o}\right)$ at time $t, c_{i y}$ is a fixed constant, $\xi_{i y, t}$ is a mean zero stationary process, which represents the error correction term of the long-run output equation, and as before $y_{i t}\left(y_{i t}^{*}\right)$ is the logarithm of real domestic (foreign) output, $e_{i t}$ is the log of the nominal exchange rate, and $p_{i t}$ is the logarithm of the domestic consumer price index $\left(\mathrm{CPI}_{i t}\right)$. As discussed in Section 2.1 in Esfahani et al. (2014), the coefficient of the variables in equation (16) have further restrictions imposed on them based on economic theory, namely

$$
\psi_{i 1}=\theta_{i}\left(1-\psi_{i 2}\right), \psi_{i 2}=\psi_{i 3}=\alpha_{i}, \text { and } \gamma_{i y}=\left(1-\alpha_{i}\right)\left(n_{i}-\theta_{i} n_{i}^{*}\right)
$$

where $\alpha_{i}$ is the share of capital in output, $n_{i}\left(n_{i}^{*}\right)$ is the domestic (foreign) population growth rate, and $\theta_{i}$ measures the extent to which foreign technology is diffused and adapted successfully by the domestic economy in the long run. In this relationship, $y_{i t}^{*}$ acts as a proxy for global technological progress. The diffusion of technology is at par with the rest of the world if $\theta_{i}=1$, while a value of $\theta_{i}$ below unity suggests inefficiency that prevents the adoption of best practice techniques, possibly due to rentseeking activities and general economic mismanagement. Note that cross-sectional regressions in the resource curse literature most likely capture short-term deviations from the steady states and in view of the substantial heterogeneity that exists across countries can be quite misleading, particularly as far as the identification of $\theta_{i}$ is concerned, which most likely could differ across countries.

Rather than combining VARX ${ }^{*}\left(p_{i}, q_{i}\right)$ models and solving the GVAR-Oil model as is done in Sect. 3.2, we test the output Eq. (16) on a country-by-country basis, imposing the additional theory restrictions in (17). To this end, we estimate individual country-specific models as before, using Eq. (12) and quarterly observations over the period 1979Q2-2011Q2, but including oil revenue $\left(o_{i t}\right)$ rather than oil prices in $\mathbf{x}_{i t}$. As predicted by the theory, we find that real output for the seven MENA oil exporters in the long run is shaped by: (i) oil revenue through its impact on capital accumulation and (ii) technological spillovers through foreign output.

We then consider the output effects of a negative unit shock (equal to one standard error) to oil revenues using the generalized impulse response functions (GIRFs), developed in Koop et al. (1996) and Pesaran and Shin (1998). ${ }^{27}$ The associated GIRFs together with their $95 \%$ error bands are shown in Fig. 9. These figures clearly show that a negative oil revenue shock significantly reduces real output in all seven countries, with the full impacts of oil revenue changes showing up in these economies quite fast, and peak within 2-3 years in most cases. The equilibrium levels of these effects are between $2 \%$ and $12 \%$ (quite heterogenous across countries), with the largest real output losses occurring in three GCC countries (Kuwait, Qatar, and the UAE) where the steady-state value of the effect of the oil revenue shock is $11-12 \%$. This difference

\footnotetext{
27 Unlike the orthogonalized impulse responses popularized in macroeconomics by Sims (1980), the GIRFs are invariant to the ordering of the variables in the VARX* model.
} 
partly reflects the much higher historical volatility of oil revenues in Kuwait (due to invasion of Kuwait by Iraq in 1990 and its aftermath) ${ }^{28}$ and Libya. The quarterly standard deviation of oil revenue for Kuwait and Libya is around $42.8 \%$ and $37.7 \%$ as compared to between $20.3 \%$ and $23.8 \%$ for the other countries.

To contrast the results for the MENA oil exporters with the other three OPEC members in our sample, we also estimated VARX* models for Ecuador, Nigeria, and Venezuela and found the results to be quite similar, see Fig. 9. In particular, the GIRFs illustrate that the equilibrium levels of these effects are between $3 \%$ and $6 \%$, with the quarterly standard deviation of oil revenue for these economies being between $19.8 \%$ and $23.2 \%$.

Overall, the results indicate that oil revenue shocks (such as those from the low oil price environment we are currently experiencing) have a large, long-lasting, and significant impact on these economies' growth paths, operating through the capital accumulation channel. Moreover, the theoretical model for major oil exporters outlined above and the fact that we could not reject the theory restrictions in (17), together with the impulse responses in Fig. 9, indicate that these countries will be adversely affected whenever the international price of crude oil declines and will benefit whenever it rises. Therefore, macroeconomic and structural polices should be conducted in a way that the vulnerability of these countries to oil revenue (not just price) disturbances are reduced, see also Cavalcanti et al. (2015), El-Anshasy et al. (2015) and Mohaddes and Raissi (2017).

The empirical results presented here have strong policy implications. Oil exporters in the MENA region and beyond are faced with substantial losses in government revenues as a result of a seemingly long-lasting oil price fall. With buffers eroding over the medium term, most countries will need to re-assess and realign their mediumterm spending plans. Improvements in the conduct of macroeconomic policies, better management of resource income volatility, and export diversification can all have beneficial growth effects; as do policies which increase the return on investment, such as public infrastructure developments and human capital enhancing measures. ${ }^{29}$ Moreover, the creation of commodity stabilization funds, or Sovereign Wealth Funds in case of countries in the Persian Gulf, might be one way to offset the negative effects of commodity booms and slumps. Finally, recent academic research has placed emphasis on institutional reform. By establishing the right institutions, one can ensure the proper conduct of macroeconomic policy and better use of resource income revenues, thereby increasing the potential for growth.

\subsection{Spillovers to MENA oil importers}

While it is no surprise that MENA oil exporters are affected negatively by lower oil prices, the overall long-term output effect for MENA oil importers is not clear cut

\footnotetext{
28 See Burney et al. (2018) for an extensive discussion.

29 For more details on oil price shocks and macroeconomic policy in resource-rich MENA countries, see, for instance, the planned edited volume "Institutions and Macroeconomic Policies in Resource-Rich Economies" (which is the outcome of an ERF funded research project) and the papers from the ERF project "Institutional Requirements for Optimal Monetary Policy in the Resource-Dependent Arab Economies" lead by Bassem Kamar.
} 

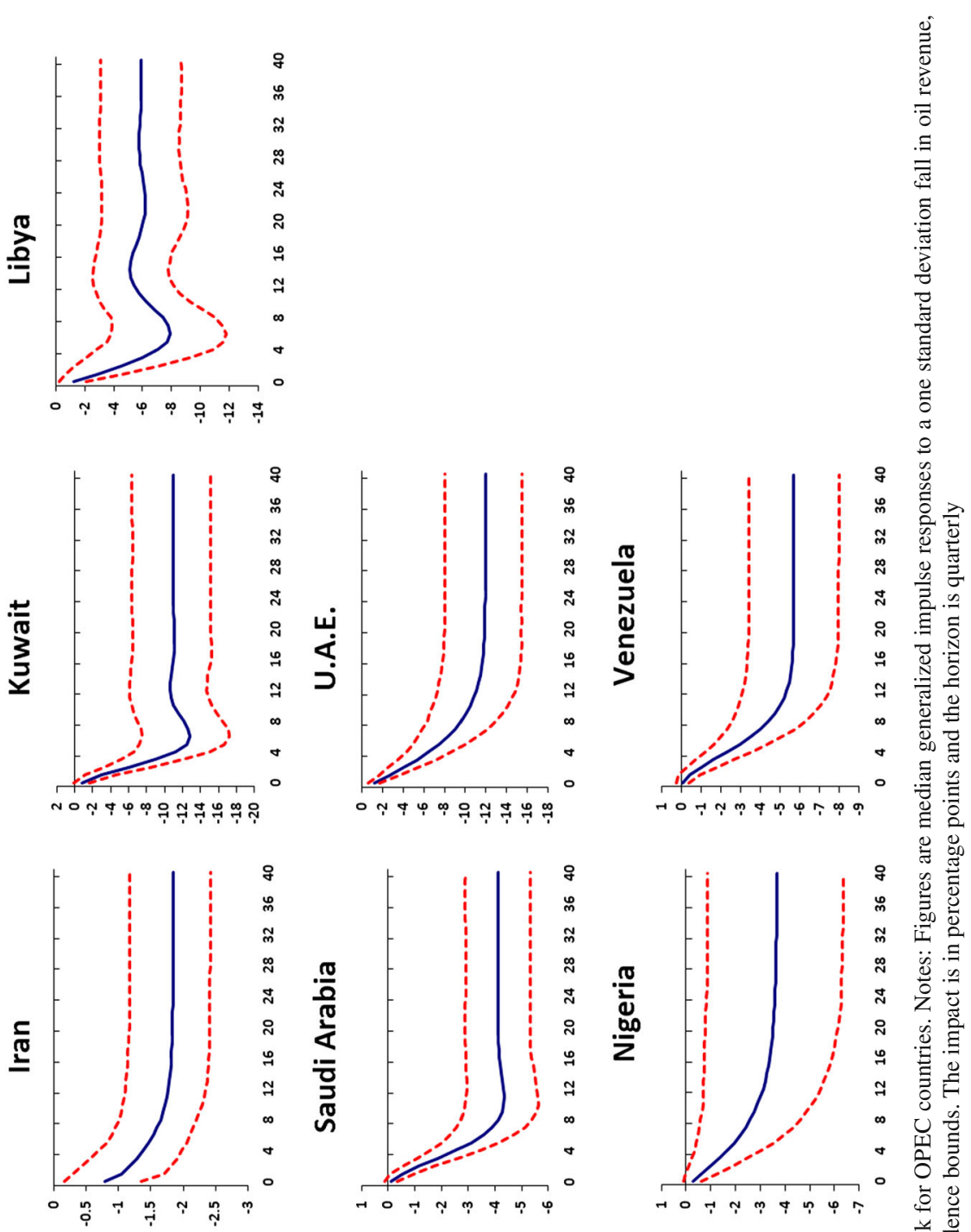

๑ :

幽苛

宓

I.

过

每

$\dot{\text { iे }}$

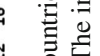

$\infty \quad \dot{0}$

- 崩 官

- 0

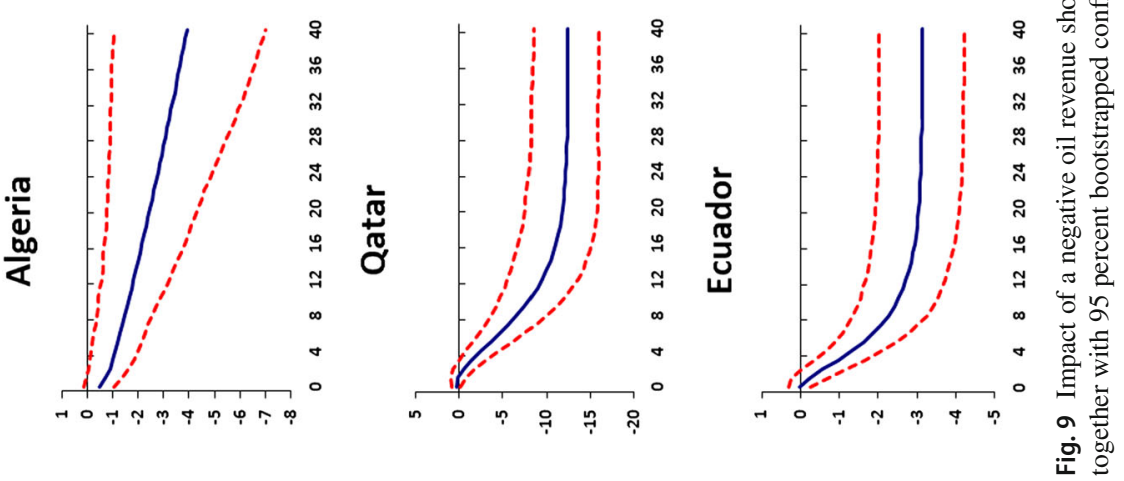




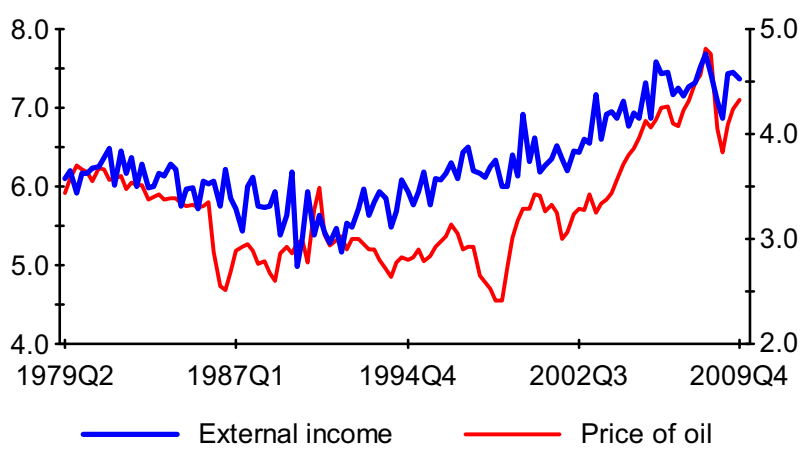

Fig. 10 External income and price of oil, in log level. Sources: Authors' construction based on data from International Monetary Fund Balance of Payments Statistics and International Financial Statistics

(considering the direct and indirect effects of lower oil prices for these economies). While a fall in oil prices initially implies lower import costs for these economies, it also reflects a slow down in oil-exporting countries (see the discussion above), which in turn negatively impact these economies through trade, remittances, and foreign direct investment (FDI) channels. Overall, Fig. 7 shows that the direct positive effect of lower oil price for all oil importers (except Egypt and Mauritania) is dominated by the indirect negative impact of spillovers from the exporters (in particular from the GCC). Below we explore the direct positive and the indirect negative channels focusing on Jordan to draw lessons for others.

Figure 10 shows the evolution of general government transfers, workers' remittances, and foreign direct investment (FDI), what we refer to as external income or $x_{i t}$. Both remittances and external income account for a significant share of Jordan's output, with the share of the former being around 15-20\% of GDP over 1979-2009 and the latter being on average $30 \%$. Given that the majority of Jordanian migrant workers reside in the neighboring GCC countries and that most of the official government transfers (grants) are received from either Saudi Arabia or the USA, any economic/political developments in the oil-exporting states of the region would significantly affect the flow of external income to Jordan. Therefore, even though the country is an oil importer, as long as $x_{i t}$ from the oil-exporting economies are maintained, we expect lower oil prices to have a long-run negative growth effect on the Jordanian economy. That is, the direct positive effect of lower oil prices is dominated by the indirect negative impact; see also International Monetary Fund (2010) and the detailed discussion in Mohaddes and Raissi (2013).

Figure 10 shows the relationship between log external income, $x_{i t}$, and log oil prices, $p_{t}^{o}$. It is clear that both variables share the same trend over the long run, with some important short-run deviations. We estimate a cointegrating VAR(2) model for external income and oil prices and find that there is a long-run relation between $x_{i t}$ and $p_{t}^{o}$. It is also interesting that the cotrending restriction, which imposes a coefficient of zero on the trend component of the long-run relationship between the two variables, is not rejected and the hypothesis that the long-run elasticity of external income to oil prices is unity cannot be rejected either, and as a result: $x_{i t}=p_{t}^{o}+\xi_{i x, t}$, where 

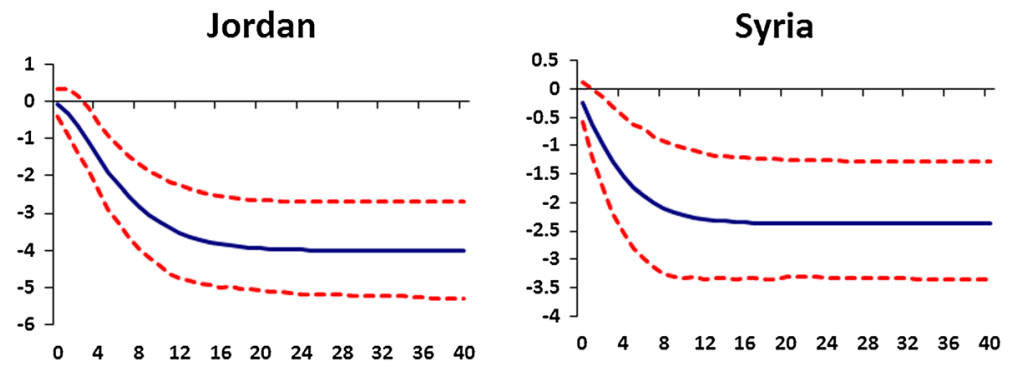

Fig. 11 Impact of a negative oil price shock. Notes: Figures are median generalized impulse responses to a one standard deviation fall in oil prices, together with $95 \%$ bootstrapped confidence bounds. The impact is in percentage points and the horizon is quarterly

$\xi_{i x, t} \sim I(0)$. Therefore, oil prices represent an excellent proxy for external income in the Jordanian economy.

Given the discussion above, we augment the output gap Eq. (16), to include oil prices as opposed to oil revenues. Note that the inclusion of $p_{t}^{o}$ will give us the net effect of lower oil prices on the equilibrium output level (the negative effect is due to less inflows of external income which in turn dampens real GDP, while the positive effect is due to the fall in the cost of importing oil), while the inclusion of $x_{i t}$ will only show the negative indirect impact of lower oil prices on GDP and not the direct positive effects. ${ }^{30}$ The modified output gap equation for Jordan is then given by

$$
y_{i t}-\psi_{i 1} y_{i t}^{*}=\psi_{i 2}\left(e_{i t}-p_{i t}\right)+\psi_{i 3} p_{t}^{o}+c_{i y}+\gamma_{i y} t+\xi_{i y, t},
$$

where all variables are defined in (16). ${ }^{31}$ We estimate a VARX*(2,2) model for Jordan, imposing the restrictions in (17), and find that we cannot reject the theory derived output relation. The results therefore confirm that a fall in oil prices, by reducing external income, dampens capital accumulation and thus leads to a fall in real output. The GIRFs in Fig. 11 illustrate the response of the Jordanian economy to a negative oil price shock (based on a historical quarterly standard deviation of $18.6 \%$ ), where the equilibrium output effect of the shock is $-4 \%$, being similar to those in Fig. 7 based on the GVAR-Oil model.

Similar analysis can also be conducted for other oil-importing countries in the MENA region. To illustrate this, we also estimated the long-run output Eq. (18) for Syria, imposing the theory restrictions above, and found that we cannot reject them. The GIRFs for Syria also show that a negative oil price shock reduces real GDP by $2.4 \%$, which is again in line with the results in Fig. 7.

\footnotetext{
30 The justification for our modeling strategy of using oil prices rather than external income as one of the main long-run drivers of real output for Jordan is given in the discussion above, where we established that the price of oil is an excellent proxy for external income. The above results also showed that from a long-run perspective, only one of the two variables $\left(x_{i t}\right.$ or $\left.p_{t}^{o}\right)$ needs to be included in the cointegrating model. Our decision to include oil prices rather than external income is further justified on the ground that $p_{t}^{o}$ is likely to be exogenous to the Jordanian economy while the same cannot be said of $x_{i t}$.

31 A similar relationship is also derived in Cavalcanti et al. (2011).
} 


\section{Concluding remarks}

We applied a set of dynamic sign restrictions on the impulse response of a GVAR-Oil model, estimated for 38 countries/regions over the period 1979Q2-2011Q2, to identify the US supply-driven oil price shock and to study the global macroeconomic implications of the resulting fall in oil prices. We quantified the GDP impact of a 10-12\% reduction in oil prices per quarter (caused by a US driven supply glut) on net energy importers and net oil exporters. We found that while oil importers typically experience a long-lived rise in economic activity (between $0.04 \%$ and $0.95 \%$ ) in response to a US supply-driven fall in oil prices, the impact is negative for energy exporters $(-2.14 \%$ for the GCC, $-1.32 \%$ for the other MENA oil exporters, and $-0.41 \%$ for Latin America) and commodity-importing countries with strong economic ties with oil exporters. Specifically, we find that for most oil importers in the MENA region, gains from lower oil prices are offset by a decline in external demand/financing by oil exporters over the medium term given strong linkages between the two groups through trade, remittances, tourism, foreign direct investment, and grants. The resulting estimated long-run negative growth effects on these countries, although being non-trivial, are much smaller than those on oil exporters; being on average $-0.28 \%$. Overall, our results suggest that following the US oil revolution, global growth increases by 0.16-0.37 percentage points. Furthermore, in response to a positive US oil supply disturbance, almost all countries in our sample experience a decrease in inflation and a rise in equity prices.

The sensitivity of MENA countries (both oil exporters and importers) to oil market developments raises the question of which policies and institutions are needed in response to such shocks. While countercyclical fiscal policies (using existing buffers) are key to insulate the exporters from commodity price fluctuations, the other priority for commodity exporters should be to enhance their macroeconomic policy frameworks and institutions (such as more autonomy in conducting the monetary and exchange rate policies). Oil importers in the region should not overestimate the positive impact of the decline in oil prices on their economies given the possibility of slowdown in oil-exporting trade partners. For the MENA countries, the current low oil price environment provides an opportunity for further subsidy and structural reforms. Finally, there is a considerable degree of nonlinearity and level dependency in the response of macroeconomic variables and oil prices to the tight oil revolution in the USA. Modeling such nonlinearity could be an avenue for future research.

Open Access This article is distributed under the terms of the Creative Commons Attribution 4.0 International License (http://creativecommons.org/licenses/by/4.0/), which permits unrestricted use, distribution, and reproduction in any medium, provided you give appropriate credit to the original author(s) and the source, provide a link to the Creative Commons license, and indicate if changes were made.

\section{References}

Alquist R, Gunette J-D (2014) A blessing in disguise: the implications of high global oil prices for the north American market. Energy Policy 64:49-57 
Arezki R, Blanchard O (2014) Seven questions about the recent oil price slump. iMFdirect

Baffes J, Kose MA, Ohnsorge F, Stocker M (2015) The Great Plunge in Oil Prices: Causes, Consequences, and Policy Responses. World Bank Policy Research Note PRS/15/01

Baumeister C, Kilian L (2015) Understanding the decline in the price of oil since june 2014. In: CEPR Discussion Paper 10404

Baxter M, Kouparitsas MA (2005) Determinants of business cycle comovement: a robust analysis. J Monet Econ 52(1):113-157

Binder M, Pesaran M (1999) Stochastic growth models and their econometric implications. J Econ Growth 4:139-183

Burney NA, Mohaddes K, Alawadhi A, Al-Musallam M (2018) The dynamics and determinants of Kuwait's long-run economic growth. Econ Model 71:289-304

Cashin P, Mohaddes K, Raissi M, Raissi M (2014) The differential effects of oil demand and supply shocks on the global economy. Energy Econ 44:113-134

Cashin P, Mohaddes K, Raissi M (2016) The global impact of the systemic economies and MENA business cycles. In: Elbadawi IA, Selim H (eds) Understanding and avoiding the oil curse in resource-rich Arab economies. Cambridge University Press, Cambridge, pp 16-43

Cashin P, Mohaddes K, Raissi M (2017b) China's slowdown and global financial market volatility: is world growth losing out? Emerg Mark Rev 31:164-175

Cashin P, Mohaddes K, Raissi M (2017a) Fair weather or foul? The macroeconomic effects of El Ni no. J Int Econ 106:37-54

Cavalcanti TVDV, Mohaddes K, Raissi M (2011) Growth, development and natural resources: new evidence using a heterogeneous panel analysis. Q Rev Econ Finance 51(4):305-318

Cavalcanti TVDV, Mohaddes K, Raissi M (2015) Commodity price volatility and the sources of growth. J Appl Econom 30(6):857-873

Cheung Y-W, Ng LK (1998) International evidence on the stock market and aggregate economic activity. J Empir Finance 5(3):281-296

Chudik A, Fratzscher M (2011) Identifying the global transmission of the 2007-2009 financial crisis in a GVAR model. Eur Econ Rev 55(3):325-339

Chudik A, Pesaran MH (2013) Econometric analysis of high dimensional VARs featuring a dominant unit. Econom Rev 32(5-6):592-649

Chudik A, Pesaran MH (2016) Theory and practice of GVAR modeling. J Econ Surv 30(1):165-197

Dees S, di Mauro F, Pesaran MH, Smith LV (2007) Exploring the international linkages of the Euro area: a global VAR analysis. J Appl Econom 22:1-38

El-Anshasy A, Mohaddes K, Nugent JB (2015) Oil, volatility and institutions: cross-country evidence from major oil producers. In: Cambridge Working Papers in Economics 1523

Elbadawi IA (2015) Thresholds matter: resource abundance, development and democratic transition in the Arab World. In: Diwan I, Galal A (eds) The Middle East economies in times of transition. Palgrave Macmillan, Basingstoke

Esfahani HS, Mohaddes K, Pesaran MH (2013) Oil exports and the Iranian economy. Q Rev Econ Finance 53(3):221-237

Esfahani HS, Mohaddes K, Pesaran MH (2014) An empirical growth model for major oil exporters. J Appl Econom 29(1):1-21

Fry R, Pagan A (2011) Sign restrictions in structural vector autoregressions: a critical review. J Econ Lit 49(4):938-60

Hamilton JD (2009) Brookings papers on economic activity, economic studies program. Brook Inst 40(1):215-283

Huang R, Masulis R, Stoll H (1996) Energy shocks and financial markets. J Futures Mark 16(1):1-27

Husain AM, Arezki R, Breuer P, Haksar V, Helbling T, Medas P, Sommer M, An IMF Staff Team (2015) Global implications of lower oil prices. In: IMF Staff Discussion Note SDN/15/15

International Monetary Fund (2010) Jordan-2010 article IV consultation-staff report and public information notice. Country Report No. 10/297

Kilian L (2009) Not all oil price shocks are alike: disentangling demand and supply shocks in the crude oil market. Am Econ Rev 99(3):1053-1069

Kilian L (2017) The impact of the fracking boom on Arab oil producers. Energy J 38(6):137-160

Kilian L, Rebucci A, Spatafora N (2009) Oil shocks and external balances. J Int Econ 77(2):181-194

Koop G, Pesaran MH, Potter SM (1996) Impulse response analysis in nonlinear multivariate models. J Econom 74:119-147 
Lee K, Pesaran MH (1993) Persistence profiles and business cycle fluctuations in a disaggregated model of UK output growth. Ric Econ 47:293-322

MacKinnon JG (1991) Critical values for cointegration tests. In: Engle R, Granger C (eds) Long-run economic relationships: readings in cointegration, Chapter 13. Oxford University Press, Oxford, pp 267-276

Mânescu CB, Nuño G (2015) Quantitative effects of the shale oil revolution. Energy Policy 86:855-866

Mohaddes K (2013) Econometric modelling of world oil supplies: terminal price and the time to depletion. OPEC Energy Rev 37(2):162-193

Mohaddes K, Pesaran MH (2014) One hundred years of oil income and the Iranian economy: A curse or a blessing? In: Alizadeh P, Hakimian H (eds) Iran and the global economy: petro populism, islam and economic sanctions. Routledge, London

Mohaddes K, Pesaran MH (2016) Country-specific oil supply shocks and the global economy: a counterfactual analysis. Energy Econ 59:382-399

Mohaddes K, Pesaran MH (2017) Oil prices and the global economy: Is it different this time around? Energy Econ 65:315-325

Mohaddes K, Raissi M (2013) Oil prices, external income, and growth: lessons from Jordan. Rev Middle East Econ Finance 9(2):99-131

Mohaddes K, Raissi M (2017) Do sovereign wealth funds dampen the negative effects of commodity price volatility? J Commodity Mark 8:18-27

Mohaddes K, Williams OH (2013) Inflation differentials in the GCC: Does the oil cycle matter? Middle East Dev J 5:2

Park J, Ratti RA (2008) Oil price shocks and stock markets in the U.S. and 13 European countries. Energy Econ 30(5):2587-2608

Peersman G, Van Robays I (2012) Cross-country differences in the effects of oil shocks. Energy Econ 34(5):1532-1547

Pesaran MH (2004) General diagnostic tests for cross section dependence in panels. In: IZA Discussion Paper No. 1240

Pesaran MH, Shin Y (1996) Cointegration and speed of convergence to equilibrium. J Econom 71:117-143

Pesaran MH, Shin Y (1998) Generalised impulse response analysis in linear multivariate models. Econ Lett 58:17-29

Pesaran MH, Shin Y, Smith RJ (2000) Structural analysis of vector error correction models with exogenous I (1) variables. J Econom 97:293-343

Pesaran MH, Schuermann T, Weiner S (2004) Modelling regional interdependencies using a global errorcorrecting macroeconometric model. J Bus Econ Stat 22:129-162

Pesaran MH, Vanessa Smith L, Smith RP (2007) What if the UK or Sweden had joined the Euro in 1999? An empirical evaluation using a global VAR. Int J Finance Econ 12(1):55-87

Sadorsky P (1999) Oil price shocks and stock market activity. Energy Econ 21(5):449-469

Sims C (1980) Macroeconomics and reality. Econometrica 48:1-48

Smith L, Galesi A (2014) GVAR toolbox 2.0. University of Cambridge: Judge Business School, Cambridge 